Article

\title{
Thermo-Hydraulic Analysis of Heat Storage Filled with the Ceramic Bricks Dedicated to the Solar Air Heating System
}

\author{
Magdalena Nemś *, Artur Nemś, Jacek Kasperski and Michał Pomorski \\ Faculty of Mechanical and Power Engineering, Wroclaw University of Science and Technology, \\ Wybrzeze Wyspianskiego 27, 50-370 Wroclaw, Poland; artur.nems@pwr.edu.pl (A.N.); \\ jacek.kasperski@pwr.edu.pl (J.K.); michal.pomorski@pwr.edu.pl (M.P.) \\ * Correspondence: magdalena.nems@pwr.edu.pl; Tel.: +48-71-320-4826
}

Received: 28 June 2017; Accepted: 10 August 2017; Published: 12 August 2017

\begin{abstract}
This article presents the results of a study into a packed bed filled with ceramic bricks. The designed storage installation is supposed to become part of a heating system installed in a single-family house and eventually to be integrated with a concentrated solar collector adapted to climate conditions in Poland. The system's working medium is air. The investigated temperature ranges and air volume flow rates in the ceramic bed were dictated by the planned integration with a solar air heater. Designing a packed bed of sufficient parameters first required a mathematical model to be constructed and heat exchange to be analyzed, since heat accumulation is a complex process influenced by a number of material properties. The cases discussed in the literature are based on differing assumptions and different formulas are used in calculations. This article offers a comparison of various mathematical models and of system operating parameters obtained from these models. The primary focus is on the Nusselt number. Furthermore, in the article, the thermo-hydraulic efficiency of the investigated packed bed is presented. This part is based on a relationship used in solar air collectors with internal storage.
\end{abstract}

Keywords: heat storage; ceramic brick material; solar air space heating system

\section{Introduction}

Energy storage is becoming an increasingly important issue. The growing world economy causes an increased demand for energy in its various forms. Such situation has been long predicted, inter alia by Starr, who suggested, in the 1990s, a graph representing an increasing role that energy storage is going to play in the global energy balance between 1980 and 2016 [1]. According to the graph, stored energy should currently cover approximately $20 \%$ of global demand and its quantity should be comparable with the quantity of energy produced from conventional sources, such as coal. The same graph forecasts that, around 2040, stored energy should account for approximately $36 \%$ global demand.

Thermal energy storage (TES) systems are mainly coupled with sources of heat whose availability and intensity vary in time, i.e., mostly with renewable energy sources, and especially with solar energy systems. Heat storage is also used in industrial waste heat recovery systems. Although charging and discharging processes usually take place at the same location, mobile heat storage units are also sometimes used to deliver heat to demand sites located at distances of up to several kilometers [2].

Current research trends focus on phase change materials (PCM) as the most promising technology for heat energy accumulation processes [3]. Some works, as well as this article, are devoted to the issue of energy storage in sensible heat storage materials. Stone thermal storage units offer many advantages, including simple design and easy maintenance, low price, and safe operation. They can also work in a broad temperature range. Research into stone heat storage enjoyed much popularity in the 1980s 
and 1990s, and resulted in many publications written at that time. This research explored inter alia the issue of pressure drop in packed beds with large-scale filling elements [4,5], experiments with a high-temperature accumulator (up to $700{ }^{\circ} \mathrm{C}$ ) [6], and a solar thermal collector with internal rock bed storage [7]. Current research dedicated to sensible heat storage materials focuses on finding operating characteristics for packed beds having a particular design and on their specific industrial applications, e.g., as a storage system in a solar power plant [8,9] or in a greenhouse [10]. Solutions dedicated to building heating systems, e.g., to achieve level temperatures on a daily basis, are less frequently proposed [11].

Further part of the article offers the results of experiments on a packed bed filled with ceramic bricks. In the future, the bed is supposed to be charged with the air coming from a concentrated solar thermal collector system adapted to climate conditions in Poland (Figure 1). In the concept design of the heating system, the packed bed functions as a long-term heat storage unit located inside the building. The unit's planned volume is dedicated to a house constructed using energy-saving technology and is initially estimated at $8 \mathrm{~m}^{3}$.

The choice of ceramic bricks as the filling material was dictated by several reasons. Structural stability can be provided more easily to a large bed filled with bricks than to a bed filled with, e.g., crushed stone or pebbles. Brick is also an easily available material and has good thermal properties. Additionally, brick is resistant to high temperatures and tolerates a high number of charge/discharge cycles. Brick does not emit any harmful gases in high temperatures, which is important, as the storage unit is to be located inside a residential house.

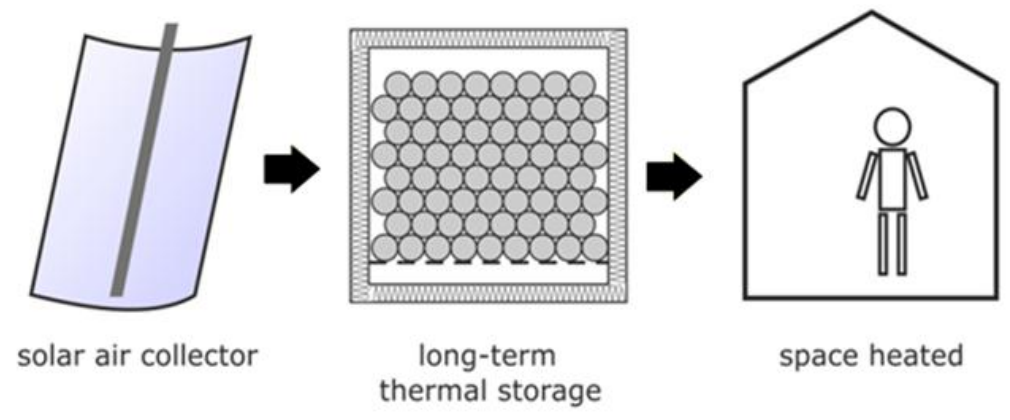

Figure 1. The concept of a solar heating system.

\section{Thermo-Hydraulic Efficiency}

The analysis of a rock heat storage system normally covers finding the amount of energy accumulated and the efficiency of the accumulation process. The authors of this article suggest that the charging process efficiency be calculated analogically to " $\eta_{\text {eff }}$ - effective efficiency" (Equation (1)) proposed in 1990 by Cortes and Piacentini [12]:

$$
\eta_{e f f}=\frac{Q_{u}-\frac{p_{m}}{g}}{I \cdot A}
$$

where $Q_{u}$ is the useful heat gain, $p_{m}$ is the mechanical energy consumed for propelling air through collector, $g$ is the constant, $I$ is the intensity of solar radiation and $A$ is the area of absorber.

Mechanical energy consumption $\left(p_{m}\right)$ for propelling air through the duct (Equation (2)) refers to mechanical energy loss due to flow resistance:

$$
p_{m}=\frac{\dot{m} \cdot \Delta p}{\rho}=\dot{V} \cdot \Delta p
$$

where $\dot{m}$ is the mass flow rate, $\Delta p$ is the pressure drop across collector length and $\rho$ is the density of fluid. Conversion efficiency $g$ is calculated from the following relationship: 


$$
g=\eta_{F} \eta_{E}\left(1-\zeta_{t}\right) \chi_{c}
$$

where $\eta_{F}$ is the efficiency of the fan, $\eta_{E}$ is the electric engine, $\zeta_{t}$ is the electric transmission loss coefficient and $\chi_{c}$ is the efficiency of thermal-electric conversion process. The assumed value was $g=0.18$ in Argentina [12] and $g=0.20$ in India [13]. This efficiency, nowadays more commonly referred to as the thermo-hydraulic efficiency, is frequently used in research papers as a means to analyze the work of solar air collectors with internal storage [14] or with additional elements improving heat exchange [15-17]. The relationship includes the amount of energy related to pressure drop in the system due to the flow resistance of the working medium.

The authors of this paper suggest that the thermo-hydraulic efficiency of the process of heat accumulation in a packed bed $\left(\eta_{t-h}\right)$ be described with Equation (4), and be defined as: the ratio between the amount of energy absorbed by the packed bed $\dot{Q}_{s}$ minus the energy lost due to the flow resistance of the working medium in the packed bed and the total amount of energy $\dot{Q}_{c}$ which could be potentially absorbed by the packed bed:

$$
\eta_{t-h}=\frac{\dot{Q}_{s}-\frac{\dot{V} \cdot \Delta p_{c}}{\eta_{f a n}}}{\dot{Q}_{c}}
$$

where $\dot{Q}_{s}$ is the heat flux absorbed by the filler material of the packed bed, $\dot{V}$ is the volumetric flow rate, $\Delta p_{c}$ is the total pressure drop in the system, $\eta_{f a n}$ is the efficiency of the fan and $\dot{Q}_{c}$ is the heat input flux. Conversion efficiency (Equation (3)) was replaced with the total efficiency of the fan. Its assumed value is 0.7 .

\section{Mathematical Model}

Calculating thermo-hydraulic efficiency for the process of charging the packed bed required the construction of a mathematical model. The model involved balance calculations of heat input and heat output to/from the heat storage device with consideration to its geometry, as described in Figure 2. Each time step was assumed to be characterized by some steady conditions. The calculations were performed with the use of a steady heat exchange equation for each step. Table 1 shows the steady parameters assumed in the calculations.

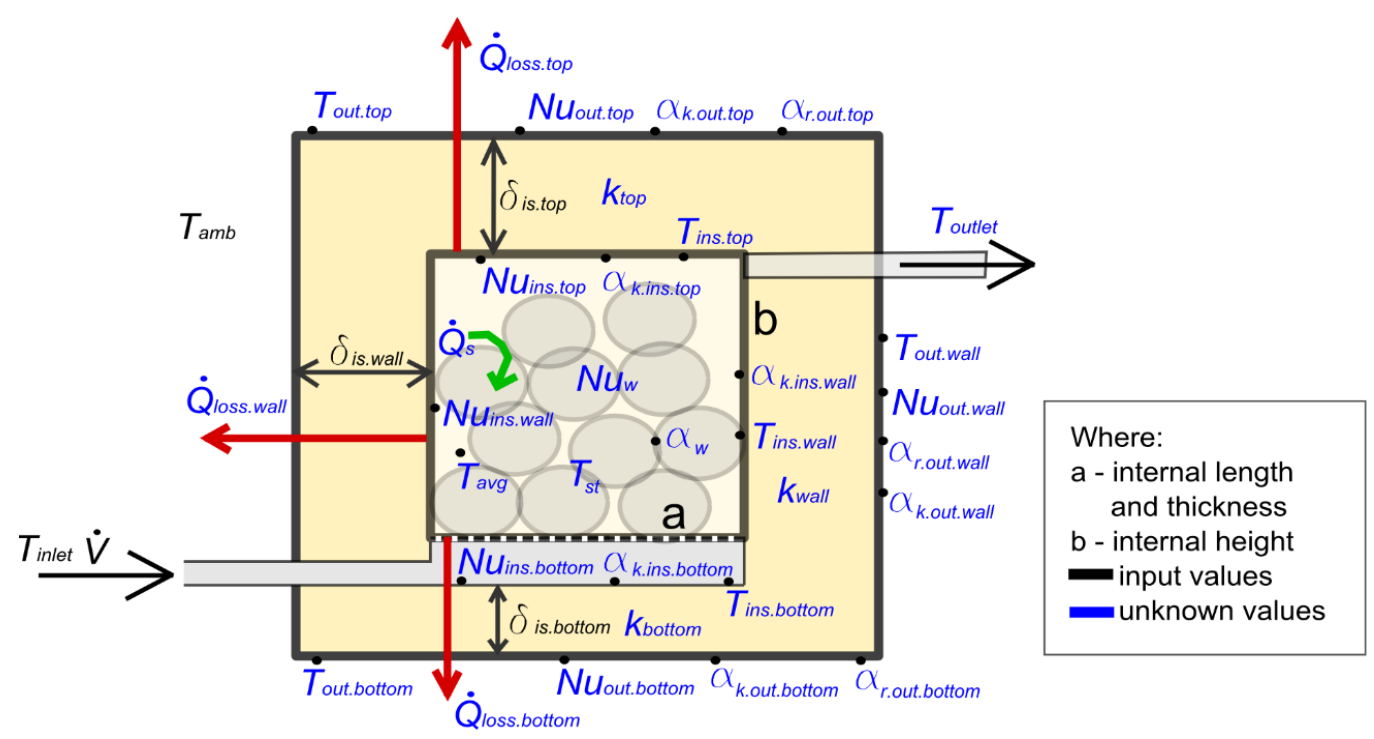

Figure 2. Scheme of the heat storage device with indicated input and calculation parameters. 
Table 1. Input parameters used in the mathematical model.

\begin{tabular}{lll}
\hline \multirow{3}{*}{ Rock bed } & Internal height & $0.5 \mathrm{~m}$ \\
& Internal thickness & $0.3 \mathrm{~m}$ \\
& Internal length & $0.3 \mathrm{~m}$ \\
\hline & Equivalent sphere diameter & $0.149 \mathrm{~m}$ \\
& Specific heat & $880 \mathrm{~J} / \mathrm{kgK}$ \\
Storage material & Density & $1800 \mathrm{~kg} / \mathrm{m}^{3}$ \\
& Porosity & 0.4 \\
& Temperature in bed 1 & $18^{\circ} \mathrm{C}$ \\
& Temperature in bed 2 & $28^{\circ} \mathrm{C}$ \\
& Mass & $40.16 \mathrm{~kg}$ \\
\hline \multirow{4}{*}{ Air } & Volumetric flow rate 1 & $0.0068 \mathrm{~m}^{3} / \mathrm{s}$ \\
& Volumetric flow rate 2 & $0.0050 \mathrm{~m}^{3} / \mathrm{s}$ \\
& Temperature inlet 1 & $220^{\circ} \mathrm{C}$ \\
& Temperature inlet 2 & $100{ }^{\circ} \mathrm{C}$ \\
& Specific heat & $\mathrm{f}(\mathrm{T})$ \\
& Density & $\mathrm{f}(\mathrm{T})$ \\
& Kinematic viscosity & $\mathrm{f}(\mathrm{T})$ \\
& Ambient temperature & $18{ }^{\circ} \mathrm{C}$ \\
\hline Insulation & Top insulation thickness & $0.20 \mathrm{~m}$ \\
& Bottom insulation thickness & $0.15 \mathrm{~m}$ \\
& Side insulation thickness & $0.15 \mathrm{~m}$ \\
& Specific heat & $0.039 \mathrm{~W} / \mathrm{mK}$ \\
\hline
\end{tabular}

Heat flux absorbed by the filler material of the packed bed $\left(\dot{Q}_{s}\right)$ is equal to heat input flux $\left(\dot{Q}_{c}\right)$ minus heat loss through the walls of the packed bed $\left(\dot{Q}_{\text {loss }}\right)$. The accumulation process does not include heat output flux $\left(\dot{Q}_{L}\right)$, which therefore has a value of zero in general Equation (5):

$$
\dot{Q}_{s}=\dot{Q}_{c}-\dot{Q}_{L}-\dot{Q}_{\text {loss }}
$$

Equation (6) describes the heat input flux:

$$
\dot{Q}_{c}=\dot{m} c_{p_{\text {air }}}\left(T_{\text {inlet }}-T_{\text {outlet }}\right) \text {, }
$$

where $\dot{m}$ is the mass flux of the air passing through the packed bed, $c_{p . a i r}$ is the heat proper of air at specific pressure, $T_{\text {inlet }}$ is the air inlet temperature, and $T_{\text {outlet }}$ is the air outlet temperature.

The flux of heat accumulated in the packed bed is described with Equation (7):

$$
\dot{Q}_{s}=\frac{m_{s t} \cdot c_{p s t} \cdot \Delta T_{s t}}{\tau},
$$

where $m_{s t}$ is the heat storage mass, $c_{p s t}$ is the specific heat of the filler material, and $\Delta T_{s t}$ is the temperature rise in the packed bed. The accumulated heat flux is equal to the heat flux transferred to the filler material (Equation (8)):

$$
\dot{Q}_{s}=\alpha_{w} \cdot S \cdot\left(T_{a v g}-T_{s t}\right),
$$

where $\alpha_{w}$ is the heat-transfer coefficient, $S$ is the area of the filler material, and $T_{\text {avg }}$ is the average temperature, described with Equation (9):

$$
T_{\text {avg }}=\frac{T_{\text {inlet }}+T_{\text {outlet }}}{2} .
$$


The heat transfer coefficient is described with Equation (10):

$$
\alpha=\frac{\lambda \cdot N u}{x}
$$

where $\lambda$ is the thermal conductivity coefficient, $N u$ is the Nusselt number and $x$ is the specific dimension. When calculating the coefficient of heat-transfer into the storage material $\alpha_{w}$, specific parameter $x$ was assumed to be $D_{\text {mat }}$, which is the diameter of a sphere having the same volume $V_{\text {mat }}$ as the volume of a single brick, calculated as in Equation (11).

$$
D_{\text {mat }}=\sqrt[3]{\frac{6 \cdot V_{m a t}}{\pi}}
$$

Equation (10) served to establish the coefficient of heat transfer from the air passing inside the packed bed to the surface of the bed walls. Specific parameter $x$ used to establish $\alpha_{k \text {.ins.wall }}$ was the height of the packed bed $b$, while the characteristic parameter used to establish $\alpha_{k \text {.ins.top }}$ and $\alpha_{k . \text { ins.bottom }}$ was the width of the packed bed $a$.

Equation (10) was also used to find the convective heat-transfer coefficient on the inside of the storage device $\alpha_{k . o u t}$. The $\alpha_{k . o u t . w a l l}$ was calculated from $x=b+2 \cdot \delta_{i s . t o p-b o t t o m}$, while the $\alpha_{k . o u t . t o p}$ and $\alpha_{k \text {.out.bottom }}$ were calculated from $x=a+2 \cdot \delta_{\text {is.wall }}$.

Nusselt number is the function of Reynolds number $(R e)$ and Prandtl number $(P r)$ :

$$
N u_{w}=A \cdot R e^{B} \cdot \operatorname{Pr} C
$$

Constants $A, B$, and $C$ in this formula describe the process of heat transfer into the filler material of the storage device.

Formula (13) describes the heat loss flux from the packed bed:

$$
\dot{Q}_{\text {loss }}=(k \cdot A) \cdot\left(T_{a v g}-T_{a m b}\right)
$$

where $k$ is the overall heat transfer coefficient, $A$ is the area, and $T_{a m b}$ is the ambient temperature.

After including the area of heat loss from the packed bed, the formula becomes Equation (14):

$$
\begin{gathered}
\dot{Q}_{\text {loss }}=\dot{Q}_{\text {loss.top }}+\dot{Q}_{\text {loss.bottom }}+\dot{Q}_{\text {loss.wall }}=\left[k_{\text {top }}\left(a+2 \delta_{i s_{\text {wall }}}\right)^{2}+k_{\text {bottom }}\left(a+2 \delta_{i s_{\text {wall }}}\right)^{2}\right] \\
+k_{\text {wall }} \cdot\left[4 \cdot\left(a+2 \delta_{i_{\text {wall }}}\right) \cdot b+\left(2 \delta_{i s_{\text {top }- \text { bottom }}}\right)\right]\left(T_{\text {avg }}-T_{\text {amb }}\right) .
\end{gathered}
$$

Equations (7), (8) and (14) served to find heat transfer flux $\dot{Q}_{s}$ and temperatures: $T_{\text {outlet }}$ and $T_{s t}$. After Equations (6) and (14) were substituted into Equation (5), the result was:

$$
\begin{gathered}
\dot{Q}_{s}=\dot{m} c_{p}\left(T_{\text {inlet }}-T_{\text {outlet }}\right)-\left[k_{\text {wall }} \cdot\left[4 \cdot\left(a+2 \delta_{i s_{\text {wall }}}\right) \cdot\left(b+2 \delta_{i s_{\text {top-bottom }}}\right)\right]\right. \\
\left.+k_{\text {bottom }}\left(a+2 \delta_{i s_{\text {wall }}}\right)^{2}+k_{\text {top }}\left(a+2 \delta_{i s_{\text {wall }}}\right)^{2}\right]\left(T_{\text {avg }}-T_{a m b}\right) .
\end{gathered}
$$

The overall coefficients of heat transfer through the housing of the packed bed are calculated from Equation (16) [18]:

$$
k=\frac{1}{\frac{1}{\alpha_{k}}+\frac{\delta_{\text {wall } 1}}{\lambda_{\text {wall } 1}}+\frac{\delta_{\text {is }}}{\lambda_{\text {is }}}+\frac{\delta_{\text {wall } 2}}{\lambda_{\text {wall } 2}}+\frac{1}{\alpha_{k}+\alpha_{r}}},
$$

where $\alpha_{k}$ is the convective heat-transfer coefficient, and $\alpha_{r}$ is the radiant heat-transfer coefficient.

To find the coefficient of heat transfer through the side wall $k_{\text {wall }}$, three coefficients were used: the coefficient of heat transfer on the inside wall $\alpha_{k \text {.ins.wall, }}$ as well as the convective coefficient $\alpha_{k . o u t . w a l l}$ and the radiant coefficient on the outside wall. Due to its negligible influence on the obtained heat flux, the resistance caused by the steel sheet used in the housing of the packed bed was disregarded 
$\frac{\delta_{\text {wall } 1}}{\lambda_{\text {wall } 1}}$ and $\frac{\delta_{\text {wall } 2}}{\lambda_{\text {wall } 2}}$-value $\delta_{i s}$ was substituted with $\delta_{i s . w a l l}$ and $\lambda_{\text {is }}$ of the insulating material. The same procedure was performed for the top surface, whose coefficient $k_{\text {top }}$ was calculated by substituting $\alpha_{k . i n s . t o p}, \alpha_{k . o u t . t o p}, \alpha_{\text {r.out.top }}$ and by assuming insulation thickness $\delta_{i \text { s.top-bottom }}$ and for the bottom surface, in which $k_{\text {bottom }}$ depended on $\alpha_{k . i n s . b o t t o m}, \alpha_{k . o u t . b o t t o m}, \alpha_{\text {r.out.bottom }}$ and on insulation thickness $\delta_{i s . t o p-b o t t o m}$.

Convective heat-transfer coefficient is calculated as in Equation (10), while radiant heat-transfer coefficient is calculated from Equation (17):

$$
\alpha_{r}=\frac{\varepsilon_{\text {wall }} \cdot \sigma \cdot\left(T_{\text {out }}^{4}-T_{a m b}^{4}\right)}{T_{\text {out }}-T_{\text {amb }}},
$$

where $\varepsilon_{\text {wall }}$ is the emissivity of the plate, $\sigma$ is the Stefan-Boltzmann constant and $T_{\text {out }}$ is the temperature of the packed bed's outside surface. The radiant coefficient of heat absorption from the side wall $\alpha_{\text {r.out.wall }}$ was calculated by assuming surface temperature $T_{\text {out.wall }}$. Coefficients $\alpha_{\text {r.out.top }}$ and $\alpha_{\text {r.out.bottom }}$ were calculated by assuming temperatures $T_{\text {out.top }}$ and $T_{\text {out.bottom, }}$, respectively.

An assumption was made that on the outside wall of the storage device's housing, heat is transferred by radiance described with Formula (17) and by natural convection. Therefore, the convective heat-transfer coefficient on the outside of the packed bed was calculated from the relationship between Nusselt number and Prandtl and Grashoff numbers (Equation (18)):

$$
N u_{o u t}=C \cdot(G r \cdot P r)^{n},
$$

where according to Kostowski [19]:

$\mathrm{Gr} \cdot \operatorname{Pr}<10^{-3}, \mathrm{C}=0.5, n=0$

$10^{-3}<\mathrm{Gr} \cdot \operatorname{Pr}<500, C=1.18, n=1 / 8$

$500 \leq \mathrm{Gr} \cdot \operatorname{Pr}<2 \cdot 10^{7}, \mathrm{C}=0.54, n=1 / 4$

$2 \cdot 10^{7} \leq \mathrm{Gr} \cdot \operatorname{Pr}, \mathrm{C}=0.135, n=1 / 3$.

For such case, the Grashoff number was calculated from Equation (19):

$$
G r=\frac{g \cdot x^{3} \frac{1}{d \frac{T_{a m b}+T_{\text {out }}}{2}}\left(T_{\text {out }}-T_{\text {amb }}\right)}{v^{2}}
$$

where $g$ is the gravitational acceleration, $x$ is the specific dimension, and $v$ is the coefficient of kinematic viscosity.

The Nusselt number was established for the outside surface of the side wall $N u_{\text {out.wall }}$ by assuming specific dimension $x$ to be $b+2 \cdot \delta_{\text {is.top-bottom }}$ and the temperature of the outside surface to be $T_{\text {out.wall }}$. At the same time, $N u_{\text {out.top }}$ was calculated by assuming $x$ to be $a+2 \cdot \delta_{\text {is.wall }}$ and the temperature of the outside surface to be $T_{\text {out.top }}$, and the assumptions for the bottom surface were analogically $x=a+2 \cdot \delta_{i s . w a l l}$ and temperature $T_{\text {out.bottom }}$.

The convective heat-transfer coefficient on the inside of the storage device was calculated from the $N u_{\text {ins }}$ Equation (20) [19] describing heat transfer during laminar flow around the plate:

$$
N u_{\text {ins }}=0.593 \cdot R e^{0.5},
$$

where, for the sidewall surface, the value of $N u_{\text {ins.wall }}$ was established by substituting specific parameter $x$ with internal height of the bed $b$, and to calculate the Nusselt number for the top surface $N u_{\text {ins.top }}$ and for the bottom surface $N u_{\text {ins.bottom }}, x$ was substituted with base length $a$.

The model included calculations made to ensure that the assumed temperatures on the walls of the housing are correct. The flux of heat loss through each of the housing layers was assumed to be constant:

$$
\dot{Q}_{\text {loss }}=\left(T_{\text {avg }}-T_{\text {ins }}\right) \cdot \alpha_{k_{\text {ins }}} \cdot A_{\text {ins }}
$$




$$
\begin{gathered}
\dot{Q}_{\text {loss }}=\left(T_{\text {out }}-T_{\text {amb }}\right) \cdot\left(\alpha_{\text {k.out }}+\alpha_{\text {r.out }}\right) \cdot \frac{A_{\text {ins }}+A_{\text {out }}}{2}, \\
\dot{Q}_{\text {loss }}=\left(T_{\text {ins }}-T_{\text {out }}\right) \cdot\left(\frac{\delta_{\text {wall } 1}}{\lambda_{\text {wall } 1}}+\frac{\delta_{\text {is }}}{\lambda_{\text {is }}}+\frac{\delta_{\text {wall } 2}}{\lambda_{\text {wall } 2}}\right) \cdot A_{\text {out }},
\end{gathered}
$$

where $T_{\text {ins }}$ is the temperature of the wall on the inside, $A_{\text {ins }}$ is the area of the inside wall and $A_{\text {out }}$ is the temperature of the wall on the outside. $A_{\text {ins }}$ for the sidewall surface was described as $A_{\text {ins.wall }}=4 \cdot a \cdot b$, and $A_{\text {out }}$ as $A_{\text {out.wall }}=4 \cdot\left(a+2 \cdot \delta_{\text {is.wall }}\right) \cdot\left(b+2 \cdot \delta_{\text {is.top.bottom }}\right)$. Meanwhile, $A_{\text {ins }}$ for the top and bottom surface was describe as $A_{\text {in.top.bottom }}=a^{2}$, and $A_{\text {out }}$ as $A_{\text {out.top.bottom }}=\left(a+2 \cdot \delta_{\text {ins.wall }}\right)^{2}$.

Equations (21)-(23) were used to find heat loss fluxes from sidewall, top and bottom surfaces of the packed bed. Values $T_{\text {ins }}, T_{\text {out }}, \alpha_{k \text {.ins }}, \alpha_{k . \text { out }}, \alpha_{\text {r.out }}$ and $\delta_{i s}$ for each surface were assumed in accordance with the labels in Figure 2, forming a set of nine equations (three per a loss flux in each direction: $\dot{Q}_{\text {loss.wall }}, \dot{Q}_{\text {loss.botttom, and }} \dot{Q}_{\text {loss.top }}$ ), which allow the calculation of unknown loss fluxes, $\dot{Q}_{\text {loss.wall, }}, \dot{Q}_{\text {loss.botttom, }}$ and $\dot{Q}_{\text {loss.top, }}$ and of the temperatures on the walls of the bed, $T_{\text {ins.wall }}, T_{\text {out.wall }}$, $T_{\text {ins.bottom }}, T_{\text {out.bottom }}, T_{\text {ins.top }}$, and $T_{\text {out.top }}$.

The working medium was air considered as a semi ideal gas. A set was obtained of 33 balance equations and 33 unknown values. The unknown values are:

- temperatures: $T_{\text {outlet }}, T_{\text {st }}, T_{\text {avg }}, T_{\text {ins.wall }}, T_{\text {out.wall }}, T_{\text {ins.bottom }}, T_{\text {out.bottom }}, T_{\text {ins.top }}$, and $T_{\text {out.top }}$;

- $\quad$ heat fluxes: $\dot{Q}_{s}, \dot{Q}_{\text {loss.wall }}, \dot{Q}_{\text {loss.botttom, }}$ and $\dot{Q}_{\text {loss.top }}$;

- $\quad$ the $\mathrm{Nu}$ numbers: $N u_{w}, N u_{\text {out.wall }}, N u_{\text {ins.wall }}, N u_{\text {ins.bottom }}, N u_{\text {out.bottom }}, N u_{\text {ins.top }}$, and $N u_{\text {out.top; }}$;

- $\quad$ heat-transfer coefficients: $\alpha_{w}, \alpha_{k . o u t . w a l l}, \alpha_{k . i n s . w a l l}, \alpha_{\text {r.out.wall }}, \alpha_{k . i n s . b o t t o m}, \alpha_{k . o u t . b o t t o m}, \alpha_{\text {r.out.bottom }}$, $\alpha_{k . \text { ins.top }}, \alpha_{k . o u t . t o p}$, and $\alpha_{\text {r.out.top; }}$ and

- $\quad$ overall heat transfer coefficients: $k_{\text {wall }}, k_{\text {bottom }}$, and $k_{\text {top }}$.

To provide an iterative solution to this system of equations, commercially available Mathcad 15.0 software was used.

The effectiveness of the accumulation process should include pressure drop in the system, which is related to the flow resistance due to the shape and the filling factor of the packed bed, analogically to the calculations for a solar thermal collector [20,21]. To find total pressure drop $\Delta p_{c}$ using the packed bed's measurement system, it was necessary to calculate the pressure drop in the bed itself and in the outlet channel, as well as the local pressure drop due to the system's geometry. Friction loss factor in the packed bed $f_{m}[14]$ is described by Equation (24):

$$
f_{m}=150 \cdot\left[\frac{1-\varepsilon_{s t}}{R e_{s t}}\right]+1.75
$$

where $\varepsilon_{s t}$ is the filling factor of the packed bed with air. Its solution required calculating the Reynolds number for the flow of the working medium through the packed bed, from Formula (25):

$$
R e_{s t}=\frac{D_{e} \cdot \rho_{a i r} \cdot w}{\mu},
$$

where $D_{e}$ is the specific dimension of the filler material, $w$ is the flow velocity of the working medium and $\mu$ is the coefficient of dynamic viscosity. The filler material's specific dimension $D_{e}$ [14] is:

$$
D_{e}=\frac{2}{3} \cdot \frac{\varepsilon_{s t} \cdot D_{m a t}}{1-\varepsilon_{s t}}
$$

The $D_{e}$ dimension used in the pressure drop formulas included equivalent diameter of the filler material $D_{\text {mat }}$. According to the literature, the equivalent diameter of the filler material can be approximated by the diameter of a sphere. Therefore, its calculation required finding the mass of 
bricks and counting the number of filler elements. The filling factor of the packed bed with air, which is required to solve Equation (22), can be calculated from Equation (27) [14]:

$$
\varepsilon_{s t}=\frac{V_{c}-n V_{m a t}}{V_{c}},
$$

where $V_{c}$ is the total bed volume.

Pressure drop in the bed, which results from transforming the formulas provided in [14,22], is described by:

$$
\Delta p_{s t}=\frac{2 \cdot \rho_{a i r} \cdot f_{m} \cdot \dot{V}^{2} \cdot b \cdot\left(\dot{1}-\varepsilon_{s t}\right)}{B^{2} \cdot D_{e} \cdot \varepsilon_{s t}^{3}},
$$

where $B$ is the bed's section area and $b$ is the bed's height. Calculating pressure drop in the outlet channel firstly required finding the Reynolds number, according to Equation (29):

$$
R e_{k}=\frac{\rho_{a i r} \cdot v_{k} \cdot D_{k}}{\mu},
$$

where $v_{k}$ is the velocity in the channel, and $D_{k}$ is the diameter of the channel. The next step consisted in using the friction coefficient $\xi$ formula, which was assumed for the turbulent flow, according to Blasius formula [23]:

$$
\xi=\frac{0.316}{R e_{k}^{0.25}} .
$$

Pressure loss due to friction during turbulent flow through a straight duct of any and uniform section, as described with the Darcy-Weisbach relationship [24], is defined as:

$$
\Delta p_{k}=\xi \cdot \frac{L_{k} \cdot v_{k}^{2} \cdot \rho_{a i r}}{4 \cdot R_{h} \cdot 2},
$$

where $L_{k}$ is the length of the duct, and $R_{h}$ is the hydraulic diameter.

In order to calculate local pressure drop due to the change of the shape and direction of flow, first it is necessary to assume a local resistance coefficient. According to tables provided in [25], a coefficient was selected for an elbow pipe with additional change of the section area of the elements: $\zeta=1.24$. Local pressure loss should be in this case proportional to the dynamic pressure of the fluid stream (31):

$$
\Delta p_{m}=\zeta \cdot \frac{v_{\mathrm{s} r}^{2} \cdot \rho_{p}}{2} .
$$

Thus, the total pressure drop in the system is described by Equation (33):

$$
\Delta p_{c}=\Delta p_{s t}+\Delta p_{k}+\Delta p_{m} .
$$

\section{The Nusselt Number}

The literature offers many formulas for calculating the Nusselt number for the flow around the storage material. Out of the available mathematical formulas, the authors chose to use those which had been applied for the filler material in the form of spheres, or which had an equivalent diameter calculated. In each of the cases, the working medium was air, considered as a semi ideal gas, for which the assumed Prandtl number was 0.7. Table 2 shows eight formulas along with their conditions of use (if such had been provided). 
Table 2. Selected Nusselt number formulas.

\begin{tabular}{ccccc}
\hline No. & Dimensionless Equation & Notes & Reference \\
\hline $\mathbf{1}$ & $N u_{w}=2+0.6 \cdot \operatorname{Re}^{0.5} \cdot \operatorname{Pr}^{1 / 3}$ & $(34)$ & $\begin{array}{c}1 \leq \operatorname{Re} \leq 70,000 \\
0.6 \leq \operatorname{Pr} \leq 400\end{array}$ & {$[19]$} \\
\hline $\mathbf{2}$ & $N u_{w}=0.8 \cdot \operatorname{Re}^{0.7} \cdot \operatorname{Pr}^{0.33}$ & $(35)$ & $500 \leq \operatorname{Re} \leq 50,000$ & {$[19]$} \\
\hline $\mathbf{3}$ & $N u_{w}=2+0.03 \cdot \operatorname{Re}^{0.54} \cdot \operatorname{Pr}^{\frac{1}{33}}+0.35 \cdot \operatorname{Re} e^{0.58} \cdot \operatorname{Pr}^{0.356}$ & $(36)$ & - & {$[26]$} \\
\hline $\mathbf{4}$ & $N u_{w}=2+1.8 \cdot \operatorname{Re}^{0.5} \cdot \operatorname{Pr}^{1 / 3}$ & $(37)$ & $\begin{array}{c}100 \leq \operatorname{Re} \text { for typical } \\
\text { gases and liquids }\end{array}$ & {$[26]$} \\
\hline $\mathbf{5}$ & $N u_{w}=2+1.1 \cdot \operatorname{Re}^{0.6} \cdot \operatorname{Pr}^{1 / 3}$ & $(38)$ & $15 \leq \operatorname{Re} \leq 8500$ & {$[27]$} \\
\hline $\mathbf{6}$ & $N u_{w}=0.29 \cdot \operatorname{Re}^{0.8} \cdot \operatorname{Pr}^{1 / 2}$ & $(39)$ & $\operatorname{Re} \leq 2400$ & {$[28]$} \\
\hline $\mathbf{7}$ & $N u_{w}=2+1.354 \cdot \operatorname{Re}^{\frac{1}{2}} \cdot \operatorname{Pr}^{\frac{1}{3}}+0.0326 \cdot \operatorname{Re} \cdot \operatorname{Pr}^{1 / 2}$ & $(40)$ & $60 \leq \operatorname{Re}$ & {$[29]$} \\
\hline $\mathbf{8}$ & $N u_{w}=0.437 \cdot R e^{0.75} \cdot \psi^{3.35} \cdot \varepsilon^{-1.62} \cdot\left[\exp \left\{29.03(\log \psi)^{2}\right\}\right]$ & $(41)$ & $\varepsilon=\frac{V_{b}-V_{s}{ }^{*}}{V_{b}}$ & {$[30]$} \\
\hline
\end{tabular}

${ }^{*} \varepsilon$ is the filling factor of the packed bed with air, $V_{b}$ is the bed volume and $V_{s}$ is the volume of the filler material;

${ }^{* *} \psi$ is the area ratio, as is the area of the sphere and ac is the area of the brick.

With the same boundary conditions selected, the above formulas provide different results. By comparing the results of actual experiments with the results from mathematical models, it will be possible to indicate the formula which best characterizes the process of thermal energy storage in ceramic bricks.

\section{Experimental Set-Up}

Figure 3 shows the experimental set-up used in the experiments on the process of heat storage. The experimental set-up comprises two metal, cuboid-shaped housings, with mineral wool inserted between them. The chosen filler material is placed in the inner housing. Both housings are made of zinc coated sheets between $1 \mathrm{~mm}$ and $3 \mathrm{~mm}$ in thickness. The remaining dimensions and operating parameters of the packed bed are provided in Table 1.

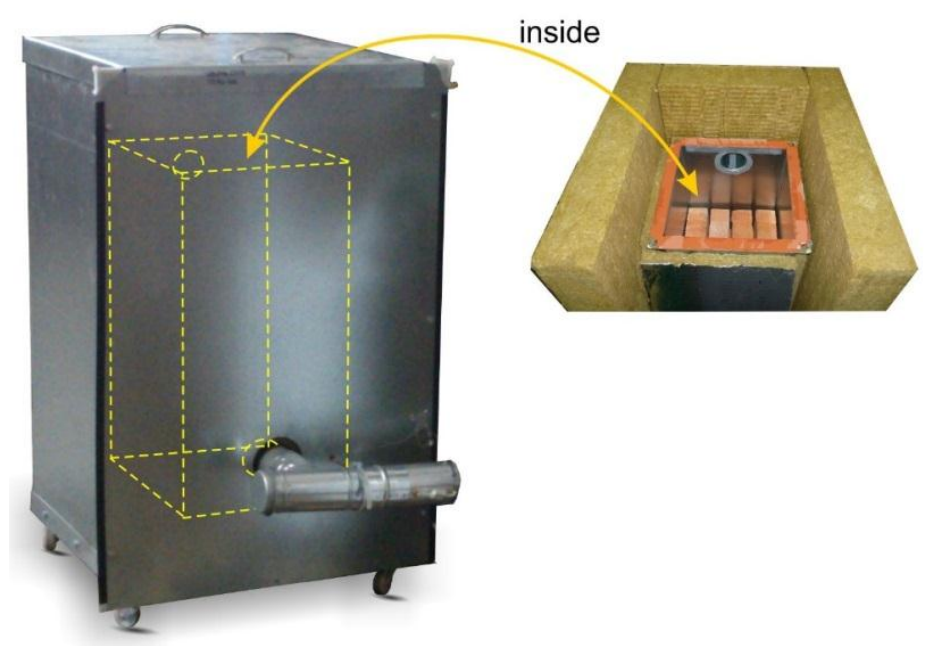

Figure 3. Experimental set-up for examining heat storage process in the rock bed. 


\subsection{The Operating Principle and the Measuring Apparatus}

Figure 4 shows a schematic diagram of the experimental set-up with the measuring apparatus.

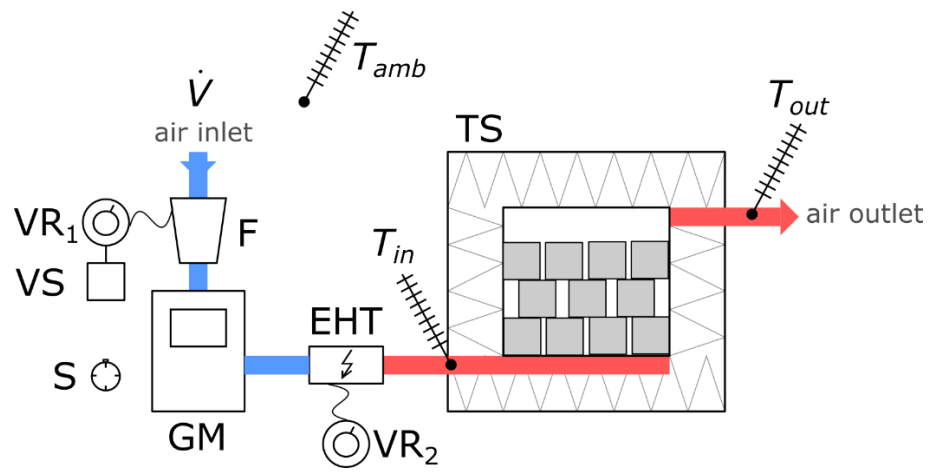

Figure 4. Schematic diagram of the experimental set-up for examining heat storage process.

Air stream $\dot{V}$ is forced into the system with fan $\mathrm{F}$. The fan is powered by autotransformer VR1, which allows changing the stream of the flowing air. Autotransformer VR1 is additionally connected to voltage regulator VS. The air then flows through gas flowmeter GM, which allows reading the volume of the flowing medium over time measured by stop watch $\mathrm{S}$. The air forced by fan $\mathrm{F}$ flows through electric heater EHT having a maximum power of $1.7 \mathrm{~kW}$, powered from autotransformer VR2. This allows regulating inlet temperature $T_{\text {in }}$. The settings of VR2 are determined experimentally and depend on the stream of airflow and on ambient temperature $T_{a m b}$. In order to flatten the velocity field, warmed airflows into packed bed TS through symmetrically distributed intake apertures, where it gives off heat to the filler material. Cooled air having temperature $T_{\text {out }}$ flows through an outlet channel located in the upper part of packed bed TS and is dissipated in the environment. The system is open-cycle.

Temperature measurement is performed with K-type thermocouples. The measured temperatures include: ambient temperature $T_{a m b}$, inlet temperature $T_{\text {in }}$ and outlet temperature $T_{\text {out }}$. The results were recorded at 60-s intervals on Lumel KD7 automatic data logger.

\subsection{Experimental Tests and Uncertainty Analysis}

The tests of heat storage process in ceramic brick were performed for two airflow rates and two different inlet temperatures. Both the airflow stream and the values of temperatures at the inlet of the medium to the packed bed were selected from a perspective of integrating the packed bed with a concentrated solar collector as part of a heating system installed in a single-family house. The parameters were selected previously, according to the analyses of the solar heater, as offered in $[20,21]$.

Initial parameters for the first and for the second experiment are shown in Table 2. Ambient temperature for both measurements was $18{ }^{\circ} \mathrm{C}$. In the second experiment, for a smaller airflow, the charging process was performed on the packed bed which was not fully discharged. The temperature of the packed bed was $28^{\circ} \mathrm{C}$, which corresponds to conditions frequently encountered in the target system. During the experiments, the end of the heat storage process was marked by the absolute increment of outlet temperature over the 10-minute period being $\Delta \mathrm{T}<2{ }^{\circ} \mathrm{C}$ for the first airflow, and $\Delta \mathrm{T}<1{ }^{\circ} \mathrm{C}$ for the second airflow.

Figure 5 illustrates the changes in the outlet temperature of air over time. The significantly different values of temperature at the inlet to the packed bed result in considerably different dynamics of the process of heat absorption by the packed bed in the first hour of the process. This fact is of importance for the construction of a model which will accurately represent the character of the process. The shape of the characteristic curve in the first hour of the charging process is of great importance also because of the planned integration of the packed bed with the heating system, where the period of time over which a certain level of direct solar radiation is available will determine the temperature at the inlet to the packed bed. 


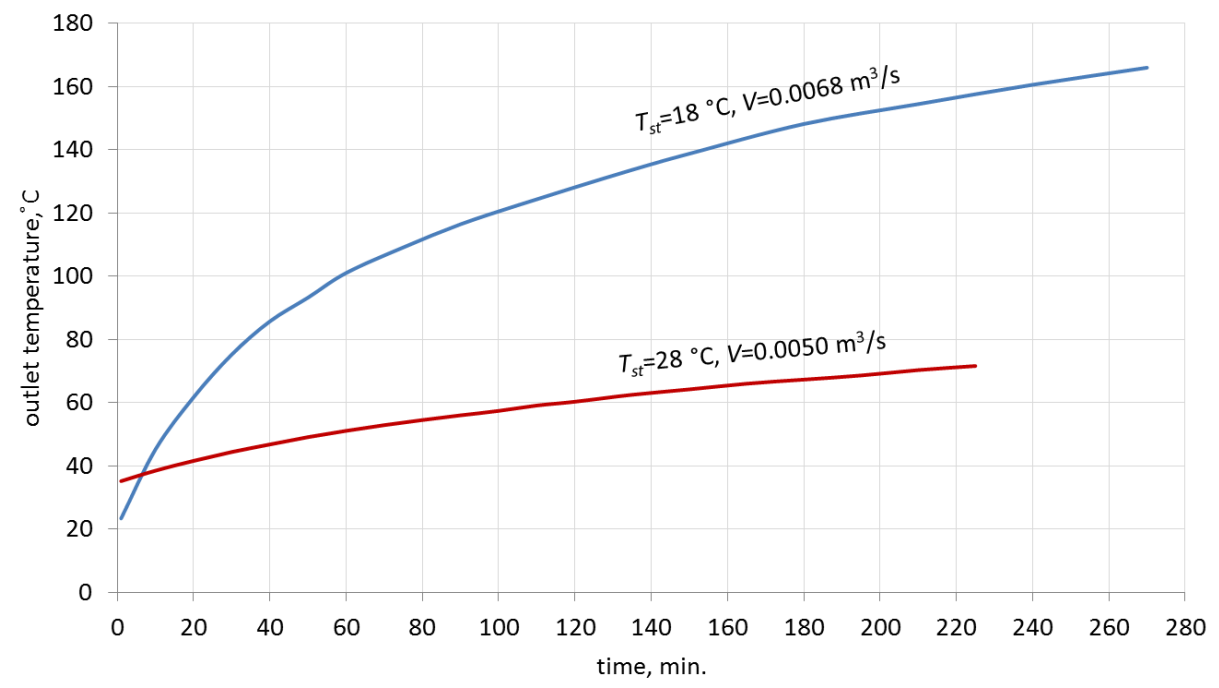

Figure 5. Change of outlet temperature as a function of charging time for two examined airflow rates.

After the experiments had been completed, the results were subjected to uncertainty analysis. The uncertainty of determining the thermo-hydraulic efficiency can be tested with the analysis of the measuring accuracy of the equipment used. The analysis of uncertainty for the equipment used in calculation of such parameters as temperature, volume flux and pressure drop was done according to the procedures described in [31]. For the calculated extended uncertainties, a coverage factor of 2 was adopted. Uncertainties, specified by the manufacturers, are: $0.1{ }^{\circ} \mathrm{C}$ for temperature, $1 \%$ for airflow in $\mathrm{m}^{3} / \mathrm{s}$ and $0.5 \mathrm{~Pa}$ for pressure drop measurement. Values of uncertainty bars were added to the characteristics represented in the next Chapter.

\section{Model Validation}

The results obtained from the balance equations described in Section 3 were compared with the results of experiments. The model included the boundary conditions obtained in experiments and the outlet temperature served as the comparative parameter. The results of analytical calculations were generated for all eight of the Nusselt number formulas. To validate the results, Equation (42) was used, which describes the deviation of outlet air temperature values obtained from the model in relation to the values obtained in the experiments:

$$
\delta T_{\text {out }}=\left|\frac{T_{\text {out }}-T_{\text {out.m }}}{T_{\text {out }}}\right| \cdot 100, \%
$$

Tables 3 and 4 show the results for the airflow of $0.0050 \mathrm{~m}^{3} / \mathrm{s}$. Tables 5 and 6 shows the results for the airflow of $0.0068 \mathrm{~m}^{3} / \mathrm{s}$. The results are presented graphically in Figures 6 and 7, respectively.

When analyzing the obtained results, one can observe that for the airflow of $0.0050 \mathrm{~m}^{3} / \mathrm{s}$, the deviations of outlet temperature are significantly lower than for the airflow of $0.0068 \mathrm{~m}^{3} / \mathrm{s}$. In the case of formula No. 1 (see Table 2), the deviations are up to $72.2 \%$ for the first airflow and up to $223.7 \%$ for the second airflow.

Figures 6 and 7 show that outlet temperatures for 6 dimensionless equations of the $N u$ number are similar to experiment results. Outlet temperatures obtained from models based on formulas Nos. 1 and 3 show the changes of outlet temperature to have a completely different character.

The results obtained for formula No. 2 were closest to the experimentally obtained results. Applying this formula for the airflow of $0.0050 \mathrm{~m}^{3} / \mathrm{s}$ resulted in the average deviation of $2.2 \%$, the maximum deviation of $3.6 \%$, and the minimum deviation of $0.4 \%$. In the case of the airflow of $0.0068 \mathrm{~m}^{3} / \mathrm{s}$, these deviations were much greater: average of $3.5 \%$, maximum of $13.2 \%$, and minimum of $0 \%$. Since formula No. 2 was assumed to sufficiently represent the character of changes in the analyzed process, it was selected for further analysis. 
Table 3. Experiment results for the airflow of $0.0050 \mathrm{~m}^{3} / \mathrm{s}$.

\begin{tabular}{|c|c|c|c|c|c|c|c|c|c|c|}
\hline \multirow{2}{*}{\multicolumn{3}{|c|}{ Experiment }} & \multicolumn{8}{|c|}{ Models } \\
\hline & & & No. 1 & No. 2 & No. 3 & No. 4 & No. 5 & No. 6 & No. 7 & No. 8 \\
\hline \multirow{2}{*}{ No. } & $t$ & $T_{o u t}$ & $T_{\text {out }}$ & $T_{\text {out }}$ & $T_{o u t}$ & $T_{\text {out }}$ & $T_{\text {out }}$ & $T_{\text {out }}$ & $T_{\text {out }}$ & $T_{\text {out }}$ \\
\hline & $\min$ & ${ }^{\circ} \mathrm{C}$ & ${ }^{\circ} \mathrm{C}$ & ${ }^{\circ} \mathrm{C}$ & ${ }^{\circ} \mathrm{C}$ & ${ }^{\circ} \mathrm{C}$ & ${ }^{\circ} \mathrm{C}$ & ${ }^{\circ} \mathrm{C}$ & ${ }^{\circ} \mathrm{C}$ & ${ }^{\circ} \mathrm{C}$ \\
\hline 1 & 1 & 35.2 & 60.6 & 34.3 & 59.8 & 40.6 & 38.1 & 39.8 & 37.7 & 42.4 \\
\hline 2 & 10 & 38.5 & 61.8 & 37.1 & 61.0 & 43.2 & 41.0 & 42.7 & 40.6 & 45.1 \\
\hline 3 & 20 & 41.6 & 63.0 & 40.4 & 62.2 & 46.4 & 44.1 & 45.7 & 43.8 & 47.9 \\
\hline 4 & 30 & 44.4 & 64.2 & 43.6 & 63.5 & 49.1 & 47.0 & 48.5 & 46.7 & 50.5 \\
\hline 5 & 40 & 46.8 & 65.2 & 46.6 & 64.6 & 51.5 & 49.7 & 51.0 & 49.4 & 52.8 \\
\hline 6 & 50 & 49.1 & 66.2 & 49.3 & 65.7 & 53.7 & 52.1 & 53.3 & 51.9 & 54.9 \\
\hline 7 & 60 & 51.1 & 67.1 & 51.8 & 66.5 & 55.5 & 54.3 & 55.3 & 54.0 & 56.8 \\
\hline 8 & 70 & 52.9 & 68.0 & 54.0 & 67.5 & 57.6 & 56.2 & 57.2 & 56.0 & 58.5 \\
\hline 9 & 80 & 54.5 & 68.8 & 56.0 & 68.4 & 59.2 & 58.0 & 58.9 & 57.8 & 60.1 \\
\hline 10 & 90 & 56.0 & 69.5 & 57.8 & 69.1 & 60.7 & 59.6 & 60.4 & 59.3 & 61.5 \\
\hline 11 & 100 & 57.4 & 70.2 & 59.4 & 69.9 & 62.1 & 61.1 & 61.8 & 61.0 & 62.8 \\
\hline 12 & 110 & 59.1 & 70.9 & 60.9 & 70.6 & 63.4 & 62.5 & 63.1 & 62.3 & 64.0 \\
\hline 13 & 120 & 60.3 & 71.5 & 62.3 & 71.2 & 64.5 & 63.7 & 64.3 & 63.6 & 65.2 \\
\hline 14 & 135 & 62.5 & 72.4 & 64.2 & 72.1 & 66.1 & 65.4 & 65.9 & 65.3 & 66.7 \\
\hline 15 & 150 & 64.2 & 73.2 & 65.8 & 73.0 & 67.5 & 66.9 & 67.4 & 66.8 & 68.0 \\
\hline 16 & 165 & 66.0 & 74.0 & 67.3 & 73.8 & 68.8 & 68.3 & 68.7 & 68.2 & 69.3 \\
\hline 17 & 180 & 67.3 & 74.7 & 68.6 & 74.5 & 70.0 & 69.5 & 69.9 & 69.4 & 70.4 \\
\hline 18 & 195 & 68.6 & 75.4 & 69.8 & 75.2 & 71.1 & 70.6 & 71.0 & 70.5 & 71.4 \\
\hline 19 & 210 & 70.3 & 76.0 & 70.9 & 75.9 & 72.0 & 71.6 & 71.9 & 71.6 & 72.4 \\
\hline 20 & 225 & 71.6 & 76.6 & 71.9 & 76.4 & 72.9 & 72.6 & 72.9 & 72.5 & 73.3 \\
\hline
\end{tabular}

Table 4. Deviations for the airflow of $0.0050 \mathrm{~m}^{3} / \mathrm{s}$.

\begin{tabular}{|c|c|c|c|c|c|c|c|c|c|c|}
\hline \multirow{2}{*}{\multicolumn{3}{|c|}{ Experiment }} & \multicolumn{8}{|c|}{ Models } \\
\hline & & & \multirow{2}{*}{$\frac{\text { No. } 1}{\delta T_{\text {out }}}$} & \multirow{2}{*}{$\begin{array}{l}\text { No. } 2 \\
\delta T_{\text {out }}\end{array}$} & \multirow{2}{*}{$\begin{array}{l}\text { No. } 3 \\
\delta T_{\text {out }}\end{array}$} & \multirow{2}{*}{$\begin{array}{l}\text { No. } 4 \\
\delta T_{\text {out }}\end{array}$} & \multirow{2}{*}{$\frac{\text { No. } 5}{\delta T_{\text {out }}}$} & \multirow{2}{*}{$\begin{array}{l}\text { No. } 6 \\
\delta T_{\text {out }}\end{array}$} & \multirow{2}{*}{$\begin{array}{l}\text { No. } 7 \\
\delta T_{\text {out }}\end{array}$} & \multirow{2}{*}{$\begin{array}{l}\text { No. } 8 \\
\delta T_{\text {out }}\end{array}$} \\
\hline \multirow{2}{*}{ No. } & $t$ & $T_{\text {out }}$ & & & & & & & & \\
\hline & $\min$ & ${ }^{\circ} \mathrm{C}$ & $\%$ & $\%$ & $\%$ & $\%$ & $\%$ & $\%$ & $\%$ & $\%$ \\
\hline 1 & 1 & 35.2 & 72.2 & 2.6 & 69.9 & 15.3 & 8.2 & 13.1 & 7.1 & 20.5 \\
\hline 2 & 10 & 38.5 & 60.5 & 3.6 & 58.4 & 12.2 & 6.5 & 10.9 & 5.5 & 17.1 \\
\hline 3 & 20 & 41.6 & 51.4 & 2.9 & 49.5 & 11.5 & 6.0 & 9.9 & 5.3 & 15.1 \\
\hline 4 & 30 & 44.4 & 44.6 & 1.8 & 43.0 & 10.6 & 5.9 & 9.2 & 5.2 & 13.7 \\
\hline 5 & 40 & 46.8 & 39.3 & 0.4 & 38.0 & 10.0 & 6.2 & 9.0 & 5.6 & 12.8 \\
\hline 6 & 50 & 49.1 & 34.8 & 0.4 & 33.8 & 9.4 & 6.1 & 8.6 & 5.7 & 11.8 \\
\hline 7 & 60 & 51.1 & 31.3 & 1.4 & 30.1 & 8.6 & 6.3 & 8.2 & 5.7 & 11.2 \\
\hline 8 & 70 & 52.9 & 28.5 & 2.1 & 27.6 & 8.9 & 6.2 & 8.1 & 5.9 & 10.6 \\
\hline 9 & 80 & 54.5 & 26.2 & 2.8 & 25.5 & 8.6 & 6.4 & 8.1 & 6.1 & 10.3 \\
\hline 10 & 90 & 56.0 & 24.1 & 3.2 & 23.4 & 8.4 & 6.4 & 7.9 & 5.9 & 9.8 \\
\hline 11 & 100 & 57.4 & 22.3 & 3.5 & 21.8 & 8.2 & 6.4 & 7.7 & 6.3 & 9.4 \\
\hline 12 & 110 & 59.1 & 20.0 & 3.0 & 19.5 & 7.3 & 5.8 & 6.8 & 5.4 & 8.3 \\
\hline 13 & 120 & 60.3 & 18.6 & 3.3 & 18.1 & 7.0 & 5.6 & 6.6 & 5.5 & 8.1 \\
\hline 14 & 135 & 62.5 & 15.8 & 2.7 & 15.4 & 5.8 & 4.6 & 5.4 & 4.5 & 6.7 \\
\hline 15 & 150 & 64.2 & 14.0 & 2.5 & 13.7 & 5.1 & 4.2 & 5.0 & 4.0 & 5.9 \\
\hline 16 & 165 & 66.0 & 12.1 & 2.0 & 11.8 & 4.2 & 3.5 & 4.1 & 3.3 & 5.0 \\
\hline 17 & 180 & 67.3 & 11.0 & 1.9 & 10.7 & 4.0 & 3.3 & 3.9 & 3.1 & 4.6 \\
\hline 18 & 195 & 68.6 & 9.9 & 1.7 & 9.6 & 3.6 & 2.9 & 3.5 & 2.8 & 4.1 \\
\hline 19 & 210 & 70.3 & 8.1 & 0.9 & 8.0 & 2.4 & 1.8 & 2.3 & 1.8 & 3.0 \\
\hline 20 & 225 & 71.6 & 7.0 & 0.4 & 6.7 & 1.8 & 1.4 & 1.8 & 1.3 & 2.4 \\
\hline \multirow{3}{*}{\multicolumn{2}{|c|}{ deviation \% }} & avg. & 27.6 & 2.2 & 26.7 & 7.7 & 5.2 & 7.0 & 4.8 & 9.5 \\
\hline & & $\max$ & 72.2 & 3.6 & 69.9 & 15.3 & 8.2 & 13.1 & 7.1 & 20.5 \\
\hline & & $\min$ & 7.0 & 0.4 & 6.7 & 1.8 & 1.4 & 1.8 & 1.3 & 2.4 \\
\hline
\end{tabular}


Table 5. Experiment for the airflow of $0.0068 \mathrm{~m}^{3} / \mathrm{s}$.

\begin{tabular}{|c|c|c|c|c|c|c|c|c|c|c|}
\hline \multirow{2}{*}{\multicolumn{3}{|c|}{ Experiment }} & \multicolumn{8}{|c|}{ Models } \\
\hline & & & No. 1 & No. 2 & No. 3 & No. 4 & No. 5 & No. 6 & No. 7 & No. 8 \\
\hline \multirow{2}{*}{ No. } & $t$ & $T_{\text {out }}$ & $T_{\text {out }}$ & $T_{\text {out }}$ & $T_{\text {out }}$ & $T_{\text {out }}$ & $T_{\text {out }}$ & $T_{\text {out }}$ & $T_{\text {out }}$ & $T_{\text {out }}$ \\
\hline & $\min$ & ${ }^{\circ} \mathrm{C}$ & ${ }^{\circ} \mathrm{C}$ & ${ }^{\circ} \mathrm{C}$ & ${ }^{\circ} \mathrm{C}$ & ${ }^{\circ} \mathrm{C}$ & ${ }^{\circ} \mathrm{C}$ & ${ }^{\circ} \mathrm{C}$ & ${ }^{\circ} \mathrm{C}$ & ${ }^{\circ} \mathrm{C}$ \\
\hline 1 & 1 & 23.4 & 75.7 & 26.5 & 74.0 & 40.7 & 34.9 & 36.2 & 33.4 & 41.5 \\
\hline 2 & 10 & 45.2 & 114.3 & 43.0 & 111.9 & 63.8 & 55.7 & 58.6 & 53.8 & 66.1 \\
\hline 3 & 20 & 61.7 & 129.6 & 59.9 & 127.3 & 80.2 & 72.5 & 75.7 & 70.8 & 82.9 \\
\hline 4 & 30 & 75.2 & 133.6 & 72.7 & 131.6 & 90.2 & 83.6 & 86.5 & 82.1 & 92.7 \\
\hline 5 & 40 & 85.7 & 137.1 & 83.9 & 135.4 & 98.9 & 93.2 & 95.8 & 92.0 & 101.2 \\
\hline 6 & 50 & 93.2 & 140.4 & 93.5 & 138.8 & 106.5 & 101.6 & 103.9 & 100.6 & 108.6 \\
\hline 7 & 60 & 101.0 & 143.3 & 101.9 & 141.9 & 113.1 & 108.9 & 110.9 & 108.0 & 115.0 \\
\hline 8 & 75 & 109.1 & 147.3 & 112.5 & 146.1 & 121.7 & 118.2 & 119.9 & 117.5 & 123.3 \\
\hline 9 & 90 & 116.4 & 150.8 & 121.2 & 149.8 & 128.8 & 125.9 & 127.4 & 125.3 & 130.2 \\
\hline 10 & 105 & 122.4 & 153.9 & 128.5 & 153.0 & 134.8 & 132.4 & 133.7 & 131.9 & 136.0 \\
\hline 11 & 120 & 128.1 & 156.6 & 134.6 & 155.9 & 140.0 & 137.9 & 139.0 & 137.5 & 141.1 \\
\hline 12 & 135 & 133.6 & 159.1 & 139.8 & 158.4 & 144.5 & 142.7 & 143.6 & 142.3 & 145.4 \\
\hline 13 & 150 & 138.7 & 161.3 & 144.3 & 160.8 & 148.4 & 146.8 & 147.6 & 146.5 & 149.2 \\
\hline 14 & 180 & 148.1 & 165.2 & 151.7 & 164.8 & 154.8 & 153.6 & 154.2 & 153.4 & 155.4 \\
\hline 15 & 210 & 154.4 & 168.4 & 157.4 & 168.1 & 159.9 & 159.0 & 159.5 & 158.8 & 160.5 \\
\hline 16 & 240 & 160.5 & 171.1 & 162.1 & 170.9 & 164.1 & 163.3 & 163.7 & 163.2 & 164.5 \\
\hline 17 & 270 & 165.9 & 173.5 & 165.9 & 173.3 & 167.5 & 166.9 & 167.2 & 166.8 & 167.9 \\
\hline
\end{tabular}

Table 6. Deviations for the airflow of $0.0068 \mathrm{~m}^{3} / \mathrm{s}$.

\begin{tabular}{|c|c|c|c|c|c|c|c|c|c|c|}
\hline \multirow{2}{*}{\multicolumn{3}{|c|}{ Experiment }} & \multicolumn{8}{|c|}{ Models } \\
\hline & & & No. 1 & No. 2 & No. 3 & No. 4 & No. 5 & No. 6 & No. 7 & No. 8 \\
\hline \multirow{2}{*}{ No. } & $t$ & $T_{\text {out }}$ & $\delta T_{\text {out }}$ & $\delta T_{\text {out }}$ & $\delta T_{\text {out }}$ & $\delta T_{\text {out }}$ & $\delta T_{\text {out }}$ & $\delta T_{\text {out }}$ & $\delta T_{\text {out }}$ & $\delta T_{\text {out }}$ \\
\hline & $\min$ & ${ }^{\circ} \mathrm{C}$ & $\%$ & $\%$ & $\%$ & $\%$ & $\%$ & $\%$ & $\%$ & $\%$ \\
\hline 1 & 1 & 23.4 & 223.7 & 13.2 & 216.2 & 74.1 & 49.2 & 54.9 & 42.6 & 77.3 \\
\hline 2 & 10 & 45.2 & 152.8 & 4.9 & 147.6 & 41.1 & 23.3 & 29.6 & 19.0 & 46.2 \\
\hline 3 & 20 & 61.7 & 110.0 & 2.8 & 106.4 & 30.0 & 17.5 & 22.6 & 14.7 & 34.4 \\
\hline 4 & 30 & 75.2 & 77.6 & 3.3 & 74.9 & 19.9 & 11.1 & 15.0 & 9.2 & 23.3 \\
\hline 5 & 40 & 85.7 & 60.0 & 2.1 & 58.0 & 15.4 & 8.8 & 11.8 & 7.3 & 18.1 \\
\hline 6 & 50 & 93.2 & 50.6 & 0.4 & 48.9 & 14.3 & 9.0 & 11.5 & 7.9 & 16.5 \\
\hline 7 & 60 & 101.0 & 41.9 & 0.9 & 40.5 & 12.0 & 7.8 & 9.8 & 7.0 & 13.9 \\
\hline 8 & 75 & 109.1 & 35.0 & 3.2 & 33.9 & 11.5 & 8.3 & 9.9 & 7.7 & 13.0 \\
\hline 9 & 90 & 116.4 & 29.5 & 4.2 & 28.7 & 10.7 & 8.2 & 9.4 & 7.7 & 11.8 \\
\hline 10 & 105 & 122.4 & 25.7 & 5.0 & 25.0 & 10.2 & 8.2 & 9.2 & 7.8 & 11.1 \\
\hline 11 & 120 & 128.1 & 22.3 & 5.1 & 21.7 & 9.3 & 7.7 & 8.5 & 7.4 & 10.1 \\
\hline 12 & 135 & 133.6 & 19.1 & 4.7 & 18.6 & 8.1 & 6.8 & 7.5 & 6.5 & 8.8 \\
\hline 13 & 150 & 138.7 & 16.3 & 4.1 & 15.9 & 7.0 & 5.8 & 6.4 & 5.6 & 7.5 \\
\hline 14 & 180 & 148.1 & 11.5 & 2.4 & 11.2 & 4.5 & 3.7 & 4.1 & 3.6 & 5.0 \\
\hline 15 & 210 & 154.4 & 9.1 & 2.0 & 8.9 & 3.6 & 2.9 & 3.3 & 2.8 & 3.9 \\
\hline 16 & 240 & 160.5 & 6.6 & 1.0 & 6.5 & 2.2 & 1.7 & 2.0 & 1.7 & 2.5 \\
\hline 17 & 270 & 165.9 & 4.6 & 0.0 & 4.5 & 1.0 & 0.6 & 0.8 & 0.5 & 1.2 \\
\hline \multirow{3}{*}{\multicolumn{2}{|c|}{ deviation \% }} & avg. & 52.7 & 3.5 & 51.0 & 16.2 & 10.6 & 12.7 & 9.3 & 17.9 \\
\hline & & max. & 223.7 & 13.2 & 216.2 & 74.1 & 49.2 & 54.9 & 42.6 & 77.3 \\
\hline & & $\min$. & 4.6 & 0.0 & 4.5 & 1.0 & 0.6 & 0.8 & 0.5 & 1.2 \\
\hline
\end{tabular}




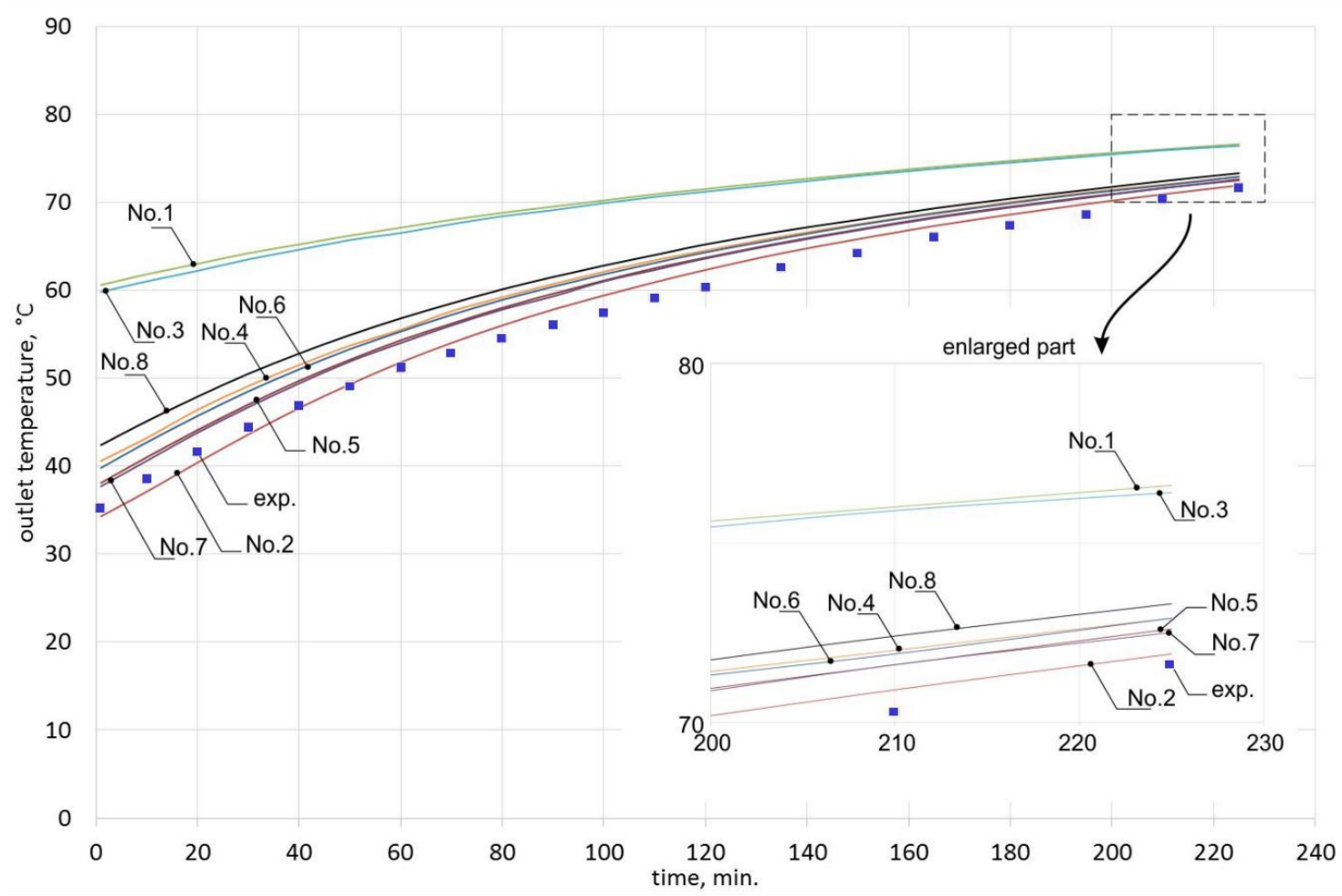

Figure 6. Outlet temperature for the airflow of $0.0050 \mathrm{~m}^{3} / \mathrm{s}$, for each of the dimensionless equations from Table 2.

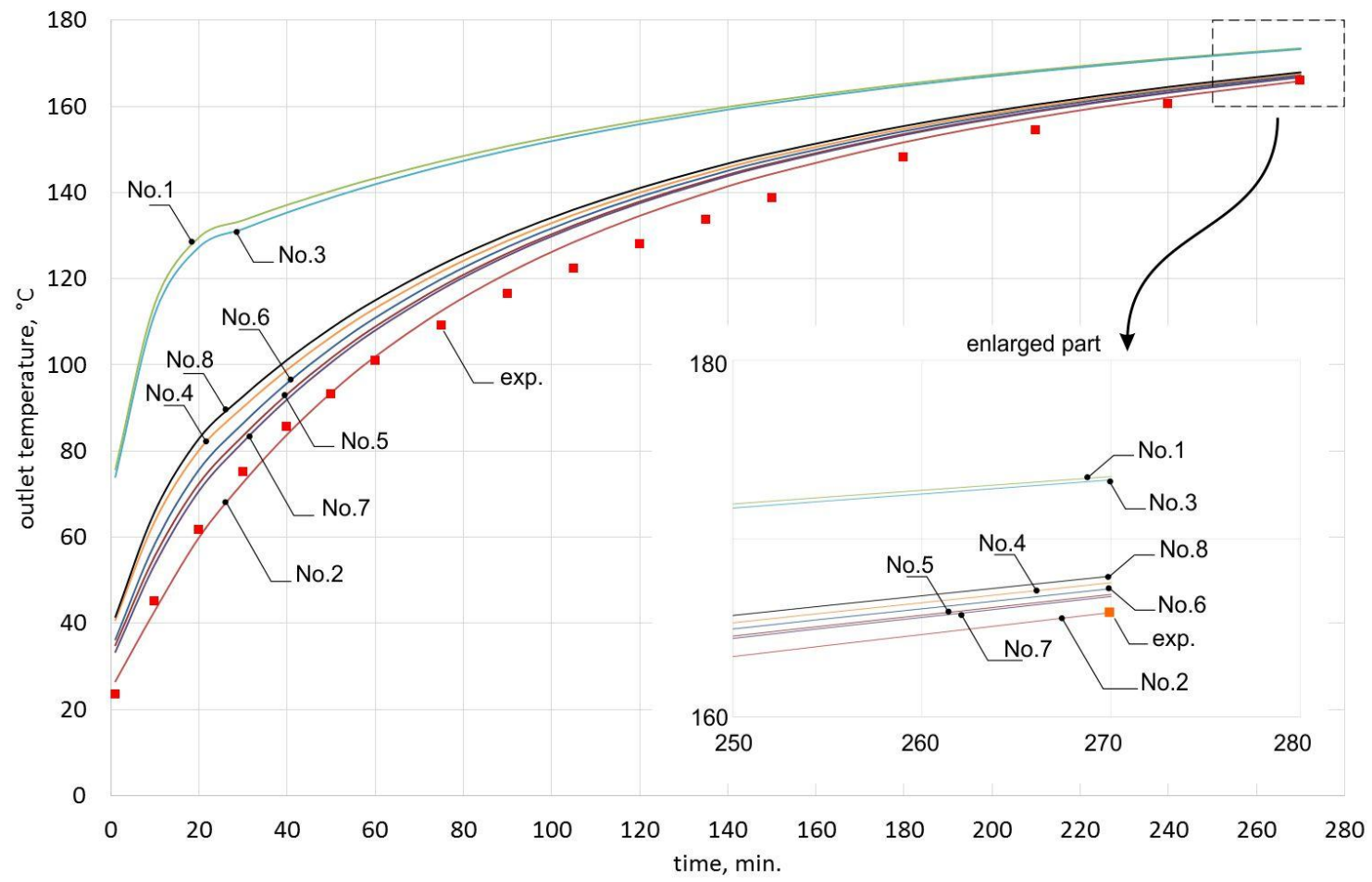

Figure 7. Outlet temperature for the airflow of $0.0068 \mathrm{~m}^{3} / \mathrm{s}$, for each of the dimensionless equations from Table 2.

Analysis of the Thermo-Hydraulic Efficiency for the Heat Storage Process in Ceramic Bricks

Calculating the thermo-hydraulic efficiency for the charging process required the measurement of pressure drops in the system. These were $1.7 \mathrm{~Pa}$ for the airflow of $0.0050 \mathrm{~m}^{3} / \mathrm{s}$, and $3.0 \mathrm{~Pa}$ for the 
airflow of $0.0068 \mathrm{~m}^{3} / \mathrm{s}$. The analytically determined pressure drops were, respectively, 1.8 Pa and 3.3 Pa. Efficiencies were calculated from Equation (4). The model results, along with the experimentally obtained data and with uncertainty bars, are presented in Figures 8 and 9.

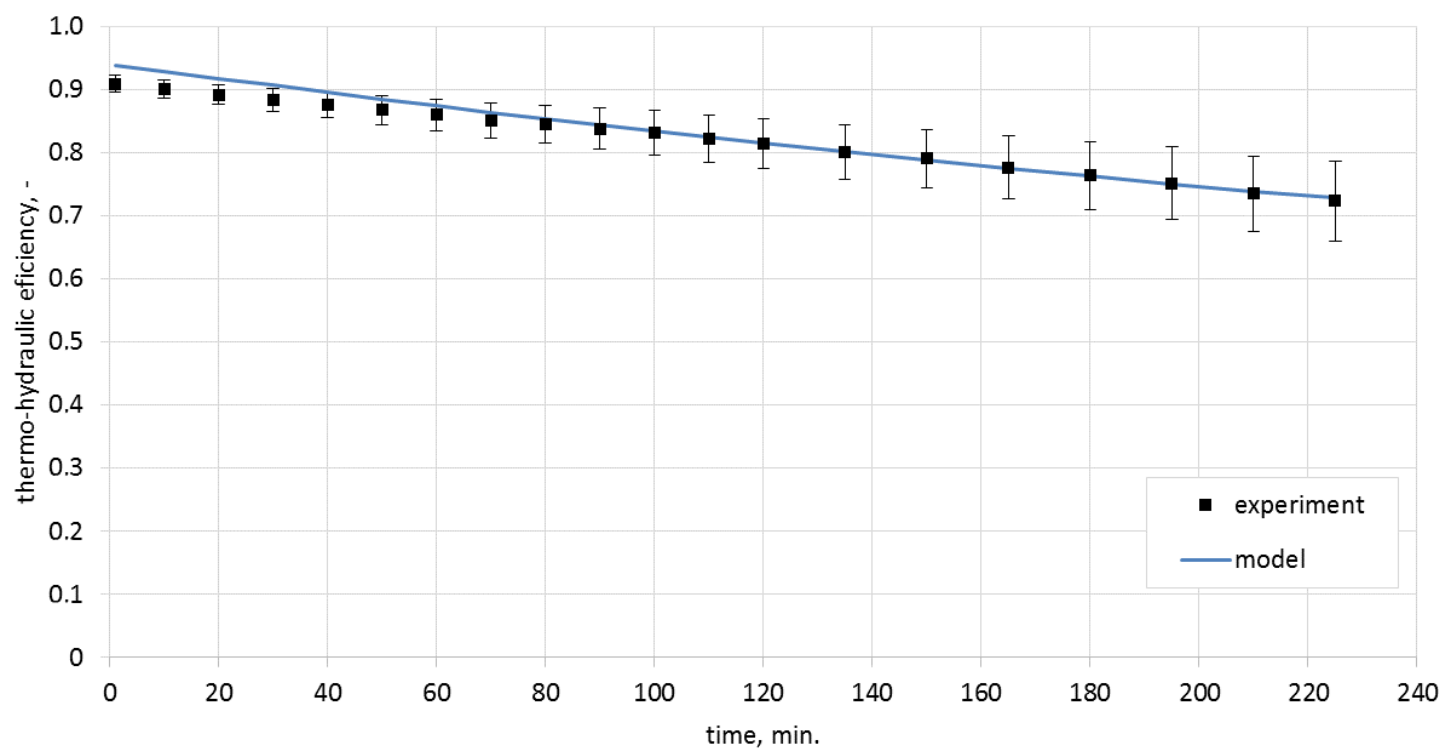

Figure 8. Thermo-hydraulic efficiency for the airflow rate of $0.0050 \mathrm{~m}^{3} / \mathrm{s}$.

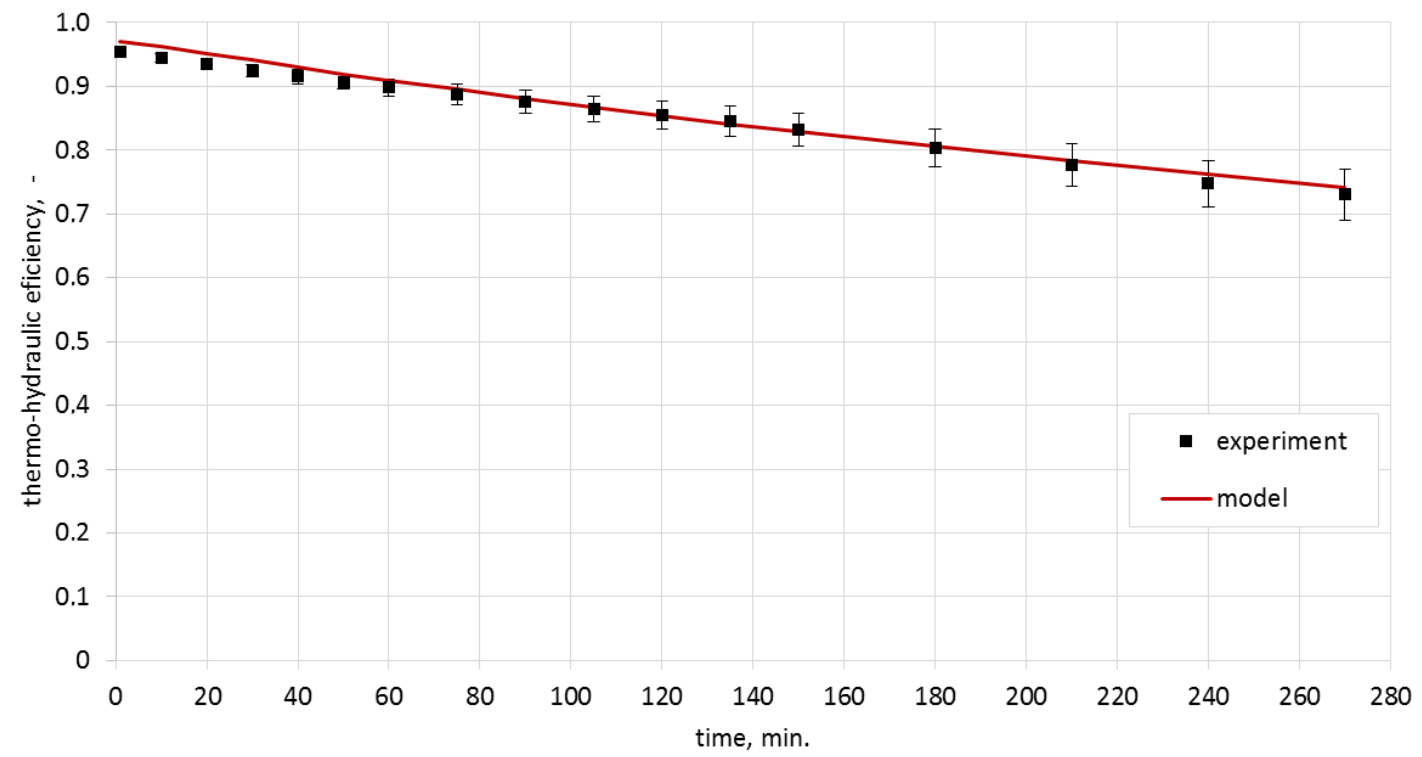

Figure 9. Thermo-hydraulic efficiency for the airflow rate of $0.0068 \mathrm{~m}^{3} / \mathrm{s}$.

The analysis of the obtained characteristics allowed concluding that the process of heat storage in ceramic brick has high efficiency which, during the experiment, was in the range of $72 \%-93 \%$ for the airflow rate of $0.0050 \mathrm{~m}^{3} / \mathrm{s}$ and $74 \%-96 \%$ for the airflow rate of $0.0068 \mathrm{~m}^{3} / \mathrm{s}$.

As shown in Figure 10, one of the reasons for the change of efficiency in time is the change of the difference between the inlet temperature and the ceramic brick temperature. Notably, the thermo-hydraulic efficiency was over $70 \%$ already for the lowest temperature differences recorded during the experiment. As can be observed in Figure 9, process efficiency for lower temperature differences can be still maintained at a constant level by limiting the airflow rate. This fact is of great importance if the storage device is integrated with a heat source of variable intensity. 


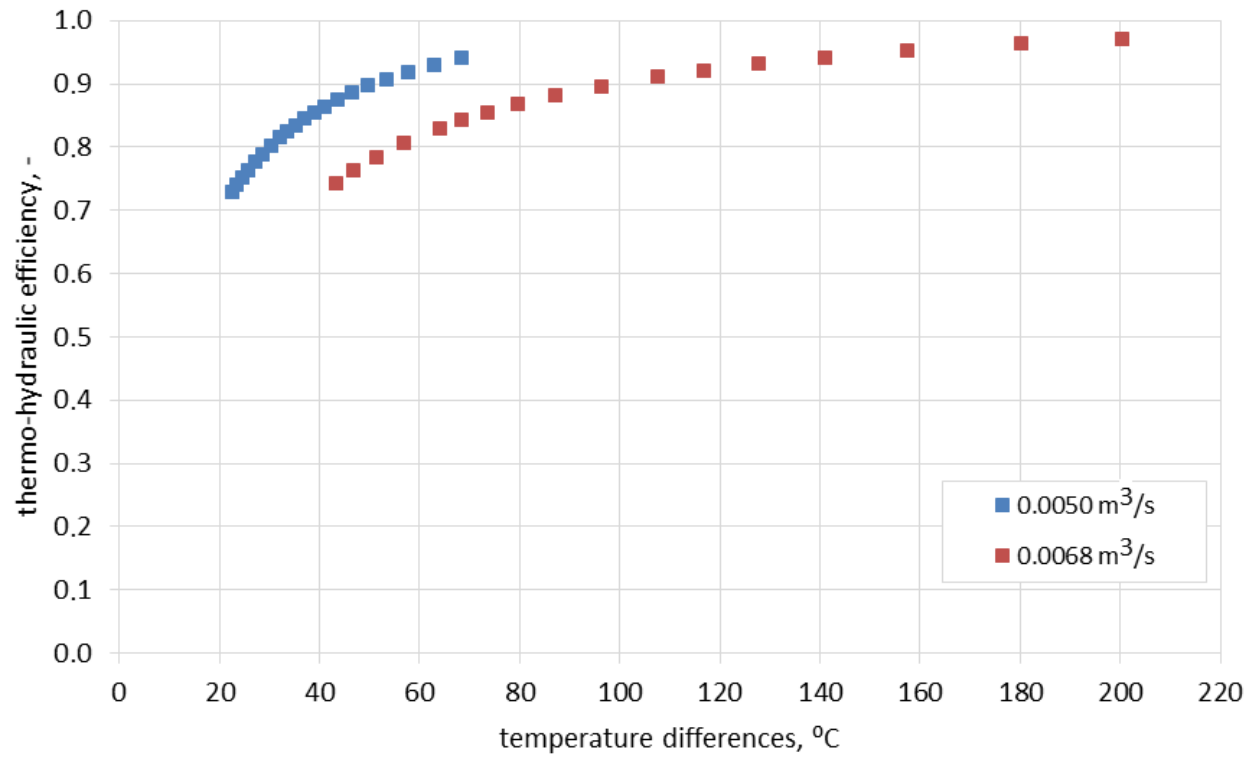

Figure 10. Thermo-hydraulic efficiency as a function of the difference between the inlet temperature and ceramic brick temperature.

In order to estimate the influence of airflow rate on the efficiency of the process, the model was used to calculate the characteristics for four inlet temperatures as a function of airflow rate and various ceramic brick temperatures (Figures 11-14).

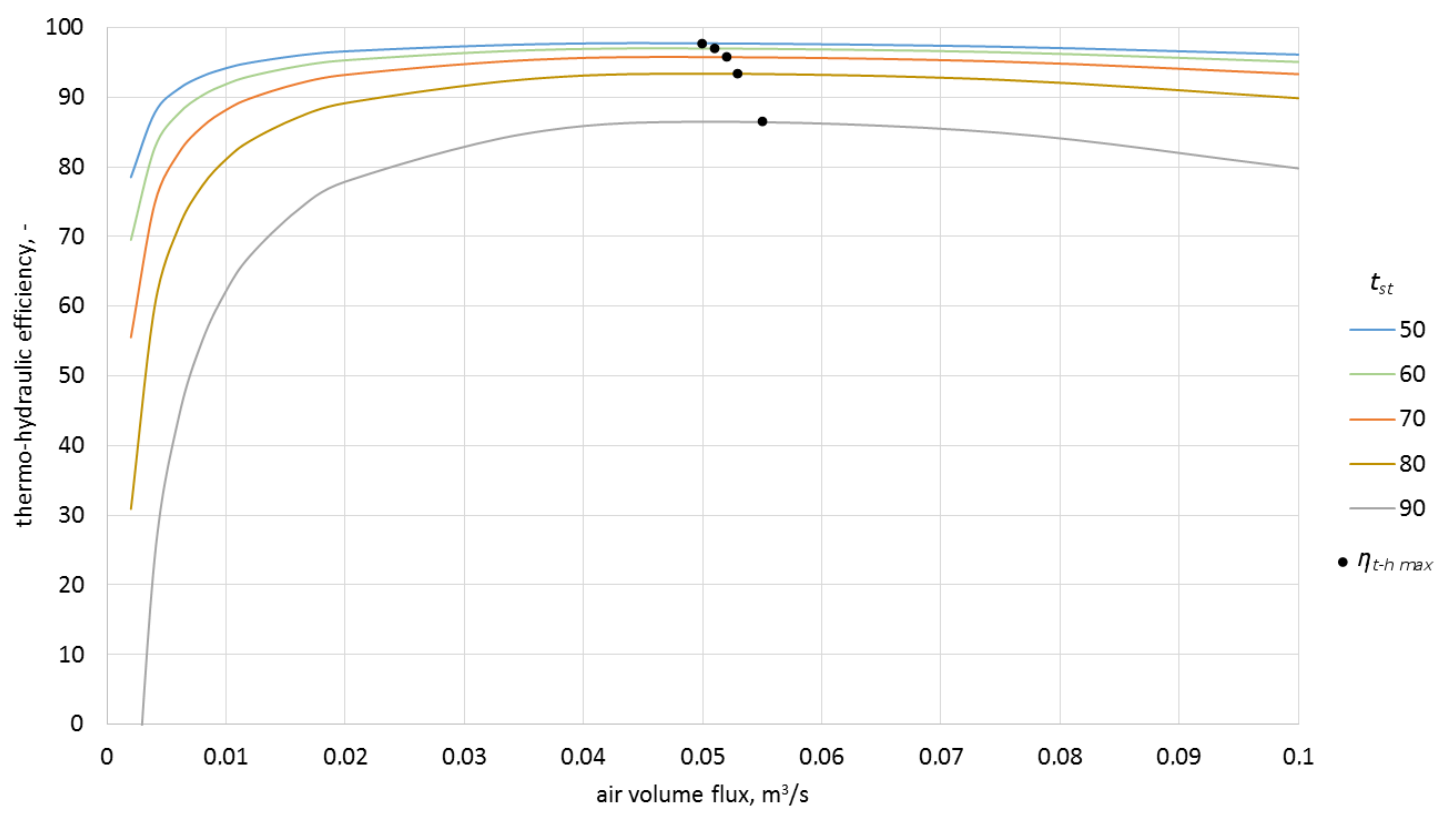

Figure 11. Thermo-hydraulic efficiency for the inlet temperature of $100^{\circ} \mathrm{C}$ and various ceramic brick temperatures. 


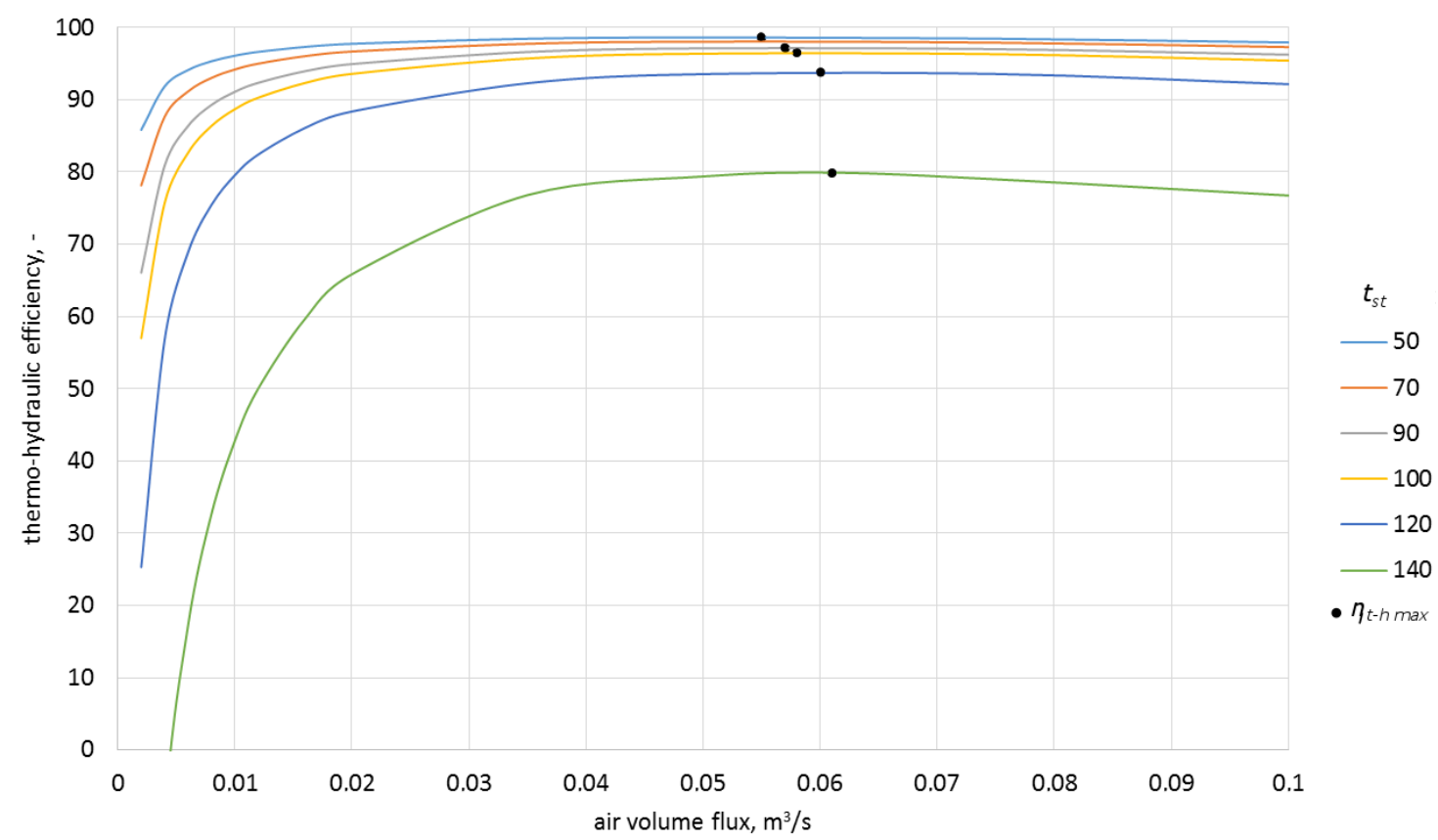

Figure 12. Thermo-hydraulic efficiency for the inlet temperature of $150{ }^{\circ} \mathrm{C}$ and various ceramic brick temperatures.

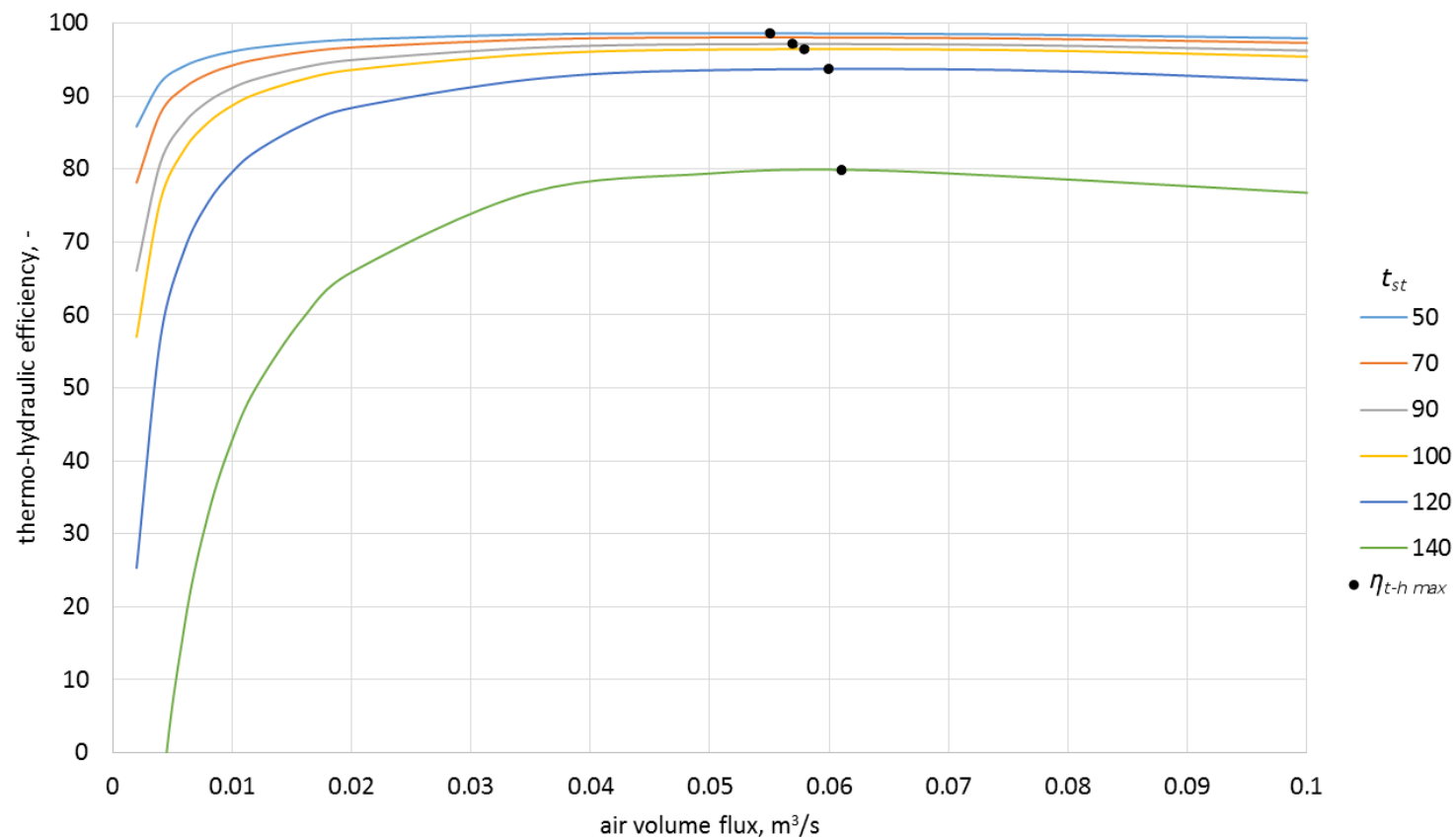

Figure 13. Thermo-hydraulic efficiency for the inlet temperature of $200{ }^{\circ} \mathrm{C}$ and various ceramic brick temperatures. 


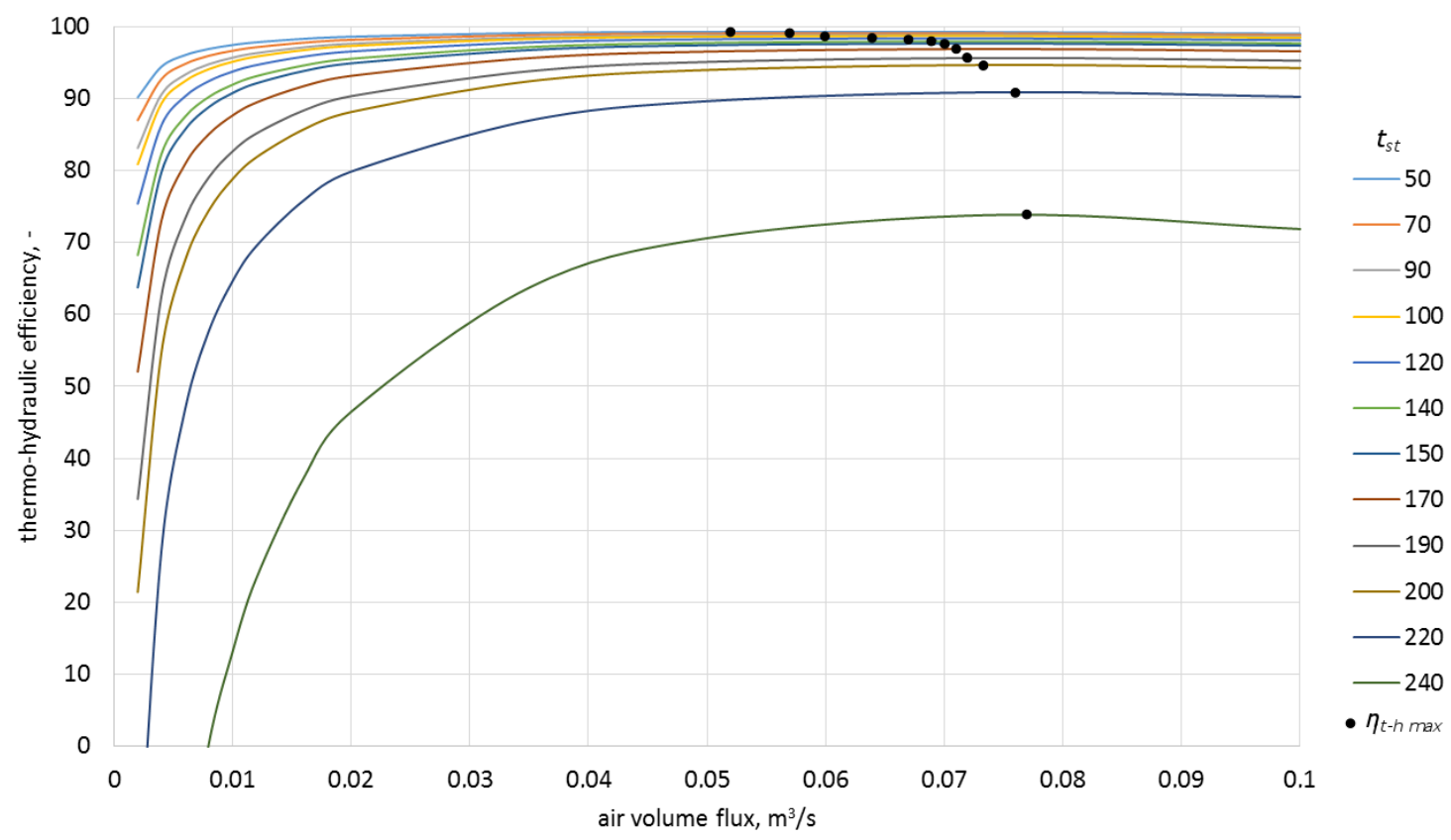

Figure 14. Thermo-hydraulic efficiency for the inlet temperature of $250^{\circ} \mathrm{C}$ and various ceramic brick temperatures.

As can be observed in the above graphs, the thermo-hydraulic efficiency in the analyzed packed bed exceeds $90 \%$ for a wide range of airflow rates. The appropriate difference between the inlet temperature and ceramic brick temperature is of importance. For the inlet temperature of up to $150{ }^{\circ} \mathrm{C}$, this difference needed to exceed $20^{\circ} \mathrm{C}$, while for the temperatures between $150{ }^{\circ} \mathrm{C}$ and $250{ }^{\circ} \mathrm{C}$, the difference needed to exceed $30{ }^{\circ} \mathrm{C}$. In the analyzed case, the thermo-hydraulic efficiency reaches maximal value for airflow rate of approximately $0.05 \mathrm{~m}^{3} / \mathrm{s}$. The $\eta_{t-h \text { max }}$ occurs when the airflow rate increases and the difference between the inlet temperature and the ceramic brick temperature decreases. The decrease in the thermo-hydraulic efficiency for greater airflow rates is caused by increasing pressure loss.

\section{Conclusions}

The thermo-hydraulic efficiency reaches maximal value for certain airflow rates and temperature difference. Such a maximum does not occur for the thermal efficiency, which increases together with increasing airflow rate. This is caused by the rapidly increasing pressure drop accompanied by the increasing speed of the working medium. The above fact means that the thermo-hydraulic efficiency is a good indicator of the economic effectiveness of the process.

As demonstrated in the above analyses, a system in which heat is stored in a sensible heat storage material, such as ceramic brick, should be provided with a means to control airflow rate in order to maximize the effectiveness of heat storage process, if the heat comes from a source of variable intensity, such as a concentrated solar air collector.

The developed model of the process of heat storage in a sensible heat storage material such as ceramic brick allows a precise description of heat storage phenomenon. The research results presented in this article are intended to aid the verification of a concept of using a sensible heat storage device coupled with a solar air heater, which may ensure thermal self-sufficiency to a residential house on a yearly basis. Therefore, the analyses in the next stage of research will cover the cooperation of the previously examined experimental set-ups with the solar collector and the packed bed to verify the assumed concept.

Acknowledgments: This work is sponsored by Ministry of Science and Higher Education in Poland under the grant for Wroclaw University of Science and Technology. Project No 0402/0232/16. 
Author Contributions: Magdalena Nemś conceived and designed the experiments, analyzed the data and designed the model; Jacek Kasperski designed the set-up; Artur Nemś analyzed the data and developed a heat exchange model; and Michał Pomorski developed a heat exchange model.

Conflicts of Interest: The authors declare no conflict of interest.

\section{References}

1. Starr, C.H. Global energy and electrical futures. Energy 1993, 18, 33-39. [CrossRef]

2. Cabeza, L.F. Surplus Heat Management Using Advanced TES for $\mathrm{CO}_{2}$ Mitigation; Final report, Annex 25; Energy Conservation through Energy Storage (ECES IA): Paris, France, 2011.

3. Mehling, H.; Cabeza, L.F. Heat and Cold Storage with PCM; Springer: Berlin, Germany, 2008.

4. Chandra, P.; Willits, D.H. Pressure drop and heat transfer characteristics of air-rockbed thermal storage systems. Sol. Energy 1981, 27, 547-553. [CrossRef]

5. Sagara, K.; Nakahara, N. Thermal performance and pressure drop of rock beds with large storage materials. Sol. Energy 1991, 47, 157-163. [CrossRef]

6. Meier, A.; Winkler, C.; Wuillemin, D. Experiment for modeling high temperature rock bed storage. Sol. Energy Mater. 1991, 24, 255-264. [CrossRef]

7. Garg, H.P.; Bandyopadhyay, B.; Sharma, V.K. Investigation of rock bed solar collector cum storage system. Energy Convers. Manag. 1981, 21, 275-282. [CrossRef]

8. Allen, K.G.; Von Backstrom, T.W.; Kroger, D.G.; Kisters, A.F.M. Rock bed storage for solar thermal power plants: Rock characteristics, suitability, and availability. Sol. Energy Mater. Sol. Cells 2014, 126, 170-183. [CrossRef]

9. Zanganeh, G.; Pedretti, A.; Zavattoni, S.; Barbato, M.; Steinfeld, A. Packed-bed thermal storage for concentrated solar power-Pilot-scale demonstration and industrial-scale design. Sol. Energy 2012, 86, 3084-3098. [CrossRef]

10. Kurklu, A.; Bilgin, S.; Ozkan, B. A study on the solar energy storing rock-bed to heat a polyethylene tunnel type greenhouse. Renew. Energy 2003, 28, 683-697. [CrossRef]

11. Abbud, I.A.; Löf, G.O.G.; Hittle, D.C. Simulation of solar air heating at constant temperature. Sol. Energy 1995, 54, 75-83. [CrossRef]

12. Cortes, A.; Piacentini, R. Improvement of the efficiency of a Bare Solar Collector by means of turbulence promoters. Appl. Energy 1990, 36, 253-261. [CrossRef]

13. Mittal, V.; Kumar, T.S. First \& Second Law Analysis of Solar Air Heater. J. Technol. Innov. Renew. Energy 2012, 1, 63-71. [CrossRef]

14. El-Sebaii, A.A.; Aboul-Enein, S.; Ramadan, M.R.I.; El-Bialy, E. Year round performance of double pass solar air heater with packed bed. Energy Convers. Manag. 2007, 48, 990-1003. [CrossRef]

15. Gupta, D.; Solanki, S.C.; Saini, J.S. Thermohydraulic performance of solar air heaters with roughened absorber plates. Sol. Energy 1997, 61, 33-42. [CrossRef]

16. Singh, S.; Dhiman, P. Thermal and thermohydraulic efficiency of recyclic-type double pass solar air heaters with fins and baffles. Heat Transf. Eng. 2016, 37, 1302-1317. [CrossRef]

17. Mittal, M.K.; Varshney, L. Optimal thermohydraulic performance of a wire mesh packed solar air heater. Sol. Energy 2006, 80, 1112-1120. [CrossRef]

18. Wisniewski, S.; Wisniewski, T.S. Heat Transfer; WNT: Warsaw, Poland, 2012.

19. Kostowski, E. A Collection of Tasks with Heat Flow; Silesian University of Technology: Gliwice, Poland, 2006.

20. Kasperski, J.; Nemś, M. Investigation of thermo-hydraulic performance of concentrated solar air-heater with internal multiple-fin array. Appl. Therm. Eng. 2013, 58, 411-419. [CrossRef]

21. Nemś, M.; Kasperski, J. Experimental investigation of concentrated solar air-heater with internal multiple-fin array. Renew. Energy 2016, 97, 722-730. [CrossRef]

22. Fernández, A.I.; Martínez, M.; Segarra, M.; Martorell, I.; Cabeza, L.F. Selection of materials with potential in sensible thermal energy storage. Sol. Energy Mater. Solar Cells 2010, 94, 1723-1729. [CrossRef]

23. Grabarczyk, C.Z. Flows in Closed Conduits. Calculation Methods; Envirotech: Poznan, Poland, 1997.

24. Jezowiecka-Kabsch, K.; Szewczyk, H. Fluid Mechanics; Publishing House of Wroclaw University of Science and Technology: Wroclaw, Poland, 2001. 
25. Pelech, A. Fundamentals of Air Conditioning and Ventilation; Publishing House of Wroclaw University of Science and Technology: Wroclaw, Poland, 2013.

26. Domanski, R. Storage of Heat Energy; PWN: Warsaw, Poland, 1990.

27. Wakao, N.; Kaguei, S.; Funazkri, T. Effect of fluid dispersion coefficients on particle-to-fluid heat transfer coefficients in packed beds: Correlation of Nusselt numbers. Chem. Eng. Sci. 1979, 34, 325-336. [CrossRef]

28. Nield, D.A.; Bejan, A. Convection in Porous Media, 3rd ed.; Springer International Publishing: Cham, Switzerland, 2006.

29. Beasley, D.E.; Clark, J.A. Transient response of packed bed for thermal energy storage. Int. J. Heat Mass Transf. 1984, 27, 1659-1669. [CrossRef]

30. Singh, R.; Saini, R.P.; Saini, J.S. Nusselt number and friction factor correlations for packed bed solar energy storage system having large sized elements of different shapes. Sol. Energy 2006, 80, 760-771. [CrossRef]

31. Kline, S.; McClintock, F. Describing uncertainties in single-sample experiments. Mech. Eng. 1953, 75, 3-8.

C 2017 by the authors. Licensee MDPI, Basel, Switzerland. This article is an open access article distributed under the terms and conditions of the Creative Commons Attribution (CC BY) license (http:/ / creativecommons.org/licenses/by/4.0/). 